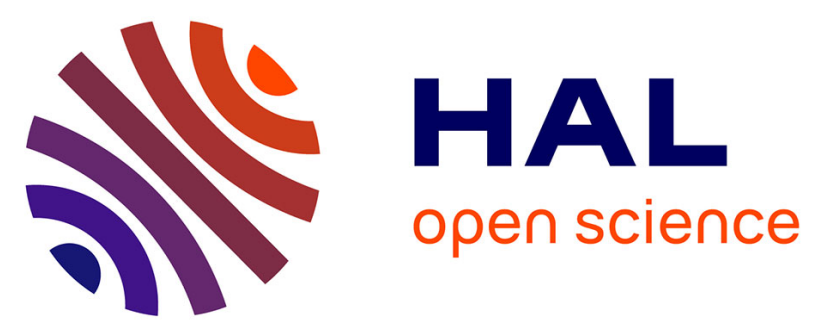

\title{
Wind-Induced Hydrodynamic Interactions With Aquatic Vegetation in a Fetch-Limited Setting: Implications for Coastal Sedimentation and Protection
}

\author{
Anne-Éléonore Paquier, Samuel Meulé, Edward J. Anthony, Philippe \\ Larroudé, Guillaume Bernard
}

\section{To cite this version:}

Anne-Éléonore Paquier, Samuel Meulé, Edward J. Anthony, Philippe Larroudé, Guillaume Bernard. Wind-Induced Hydrodynamic Interactions With Aquatic Vegetation in a Fetch-Limited Setting: Implications for Coastal Sedimentation and Protection. Estuaries and Coasts, 2018, 42 (3), pp.688-707. 10.1007/s12237-018-00487-w . hal-01964253

\section{HAL Id: hal-01964253 \\ https://hal.science/hal-01964253}

Submitted on 16 Aug 2021

HAL is a multi-disciplinary open access archive for the deposit and dissemination of scientific research documents, whether they are published or not. The documents may come from teaching and research institutions in France or abroad, or from public or private research centers.
L'archive ouverte pluridisciplinaire HAL, est destinée au dépôt et à la diffusion de documents scientifiques de niveau recherche, publiés ou non, émanant des établissements d'enseignement et de recherche français ou étrangers, des laboratoires publics ou privés. 


\title{
Wind-Induced Hydrodynamic Interactions With Aquatic Vegetation in a Fetch-Limited Setting: Implications for Coastal Sedimentation and Protection
}

\author{
Anne-Eleonore Paquier ${ }^{1}$ (D) $\cdot$ Samuel Meulé ${ }^{1} \cdot$ Edward J. Anthony $^{1} \cdot$ Philippe Larroudé $^{2} \cdot$ Guillaume Bernard $^{3}$
}

\begin{abstract}
Interactions between a patchy degraded Zostera noltei seagrass meadow and waves, currents, and sedimentary processes were analyzed from data obtained from a strongly wind-influenced micro-tidal brackish water lagoon in southeastern France. Measurements were conducted on offshore and foreshore morphology (topography, bathymetry), on hydrodynamics (waves, water levels, and currents) under different wind conditions within and outside the meadow, and on meadow biometry (shoot density, leaf length). The main impact of this patchy meadow on wind-wave transformations seems to be attenuation of waves further offshore than in the absence of vegetation. This attenuation is particularly notable above the meadow front edge, and is related to wave heights, water levels, and wave periods that are, in turn, dependent on wind intensity and fetch length. The data show that the patchy meadow does not attenuate small and short waves, especially when water levels are high, but is capable, like salt marshes and artificial seagrass, of attenuating relatively high and long waves. Notwithstanding its patchy and degraded character, the meadow also strongly influences the vertical distribution of currents. Whereas currents are strong and significantly influenced by wind and wind waves above the meadow, both waves and currents are dissipated in a transitional canopy-water layer. These wave and current modifications are reflected in the evolution of the seabed. Erosion and sedimentation are mainly controlled by the hydrodynamics but the seasonal state of the meadow plays a role by modulating the hydrodynamics. These substrate changes are, important, in turn, in influencing protection of the shoreline.
\end{abstract}

Keywords Hydrodynamics · Morphodynamics - Zostera noltei . Seagrass meadows · Wind waves · Current · Turbulence · Fetch-limited setting

\section{Introduction}

Seagrass meadows are increasingly subject to human pressures around the world, and many are located in disturbed coastal

Anne-Eleonore Paquier

paquier@cerege.fr

1 Aix Marseille University, CNRS, IRD, INRA, Coll France, CEREGE, Aix-en-Provence, France

2 Grenoble INP (Institute of Engineering University, Grenoble Alpes), CNRS, LEGI, University Grenoble Alpes, 38000 Grenoble, France

3 GIPREB (Gestion Intégrée, Prospective et Restauration de l'Étang de Berre) Syndicat Mixte, Cours Mirabeau, 13330 Berre l'Étang, France ecosystems, and are, therefore, rapidly declining (Waycott et al. 2009). The need to protect them is justified by the various coastal ecosystem services they provide, including shelter for fishes and fish spawning sites (Gillanders 2006), and shoreline stabilization (Short et al. 2007; Boudouresque et al. 2016). Seagrass meadows are significantly influenced by the hydrodynamic and sedimentary context in which they thrive, but they also strongly modify this context. These aquatic plants are, like mangroves (Barbier et al. 2008) and salt marshes (Paquier et al. 2016), undisputedly ecological engineering actors in coastal protection, in the sense described by Borsje et al. (2011). As highlighted by Ondiviela et al. (2014), various species of seagrass meadows are widely known to attenuate waves (Fonseca and Cahalan 1992; Bradley and Houser 2009; Manca et al. 2012; Paul et al. 2012; Koftis et al. 2013), and currents (Fonseca et al. 1982; Fonseca and Fisher 1986; Peterson et al. 2004; Bouma et al. 2007; Widdows et al. 2008), and to significantly influence sediment dynamics (Wanless 1981; Madsen et al. 2001; Chen et al. 2007; De Boer 2007; Ganthy et al. 2011a; Boscutti et al. 2015). 
Wave attenuation by seagrass meadows has been shown to vary as a function of wave height and wave period (Lowe et al. 2007; Bradley and Houser 2009; Manca et al. 2012), and to decrease under the effect of a stationary current (Paul et al. 2012). The biometric characteristics of a meadow, notably shoot density (Paul and Amos 2011; Koftis et al. 2013), leaf-area index (Paul et al. 2012), plant stiffness (Bouma et al. 2005; Paul et al. 2012), submergence ratio (Méndez et al. 1999; Bouma et al. 2005; Stratigaki et al. 2011; Manca et al. 2012; John et al. 2016), and meadow morphological attributes such as extension (Chen et al. 2007) and fragmentation (Fonseca and Koehl 2006), have also been shown to be control factors in the ability of a meadow to attenuate waves and reduce current velocities (John et al. 2016). To initiate wave and current attenuation in a given meadow, a minimum shoot density is required (Paul and Amos 2011). Koftis et al. (2013) showed from a flume study that wave dampening increased with shoot density and with a higher submergence ratio (height of seagrass/water depth). Méndez et al. (1999) demonstrated, in a numerical study validated by experimental laboratory data, that dissipation increased with vegetation height in a given water column. These results imply that, for a given canopy height, a higher water level (i.e., generated by wind setup, pressure gradients or tides) can lead to a decrease in wave attenuation. Hydrodynamic attenuation is thus specific to each species (Elginoz et al. 2011) and depends on water depths and meadow characteristics. Seasonal variations in shoot density can also generate variations in wave attenuation as shown by a field study of Paul and Amos (2011). Christianen et al. (2013) showed the ability of a short, low-biomass, heavily grazed seagrass meadow to reduce wave-induced sediment erosion. Notwithstanding, the question of the influence of a patchy degraded meadow on hydrodynamics and substrate stability has rarely been studied.

The interactions between seagrass and current flow are characterized by high shear stress and high turbulence at the canopywater interface and lower mean velocities and turbulence in the below-canopy habitat (Gambi et al. 1990). These interactions vary as a function of shoot density. Moderate shoot-density meadows (Peralta et al. 2008) and patchy low shoot-density meadows (Worcester 1995) allow for relatively high mean current velocities within the canopy. High shoot-density meadows reduce current velocities by reorienting high flow from the near-bed area to the top of the canopy, developing a skimming flow above the canopy (Gambi et al. 1990; Peralta et al. 2008; Stratigaki et al. 2011). Whereas some authors have observed turbulence increases in the canopy (Fonseca and Koehl 2006), particularly near the bed (Pujol and Nepf 2012), others have observed that turbulence is relatively enhanced in low shoot-density canopies but reduced in dense canopies (Hansen and Reidenbach 2017).

Hydrodynamics and sediment dynamics can have a significant influence on the meadow itself. Currents and waves can limit the spread of seagrasses (Madsen et al. 2001). The literature shows contradictory reported or expected effects of wave attenuation on meadows. These contradictory effects are probably related to wave-current, wave-plant, and current-plant interaction patterns, as well as vegetation characteristics, the range of all of which must be extremely variable from one meadow site to another. Bouma et al. (2005) considered wave attenuation as beneficial to seagrass meadows because it enabled settling of sediments within the vegetated zone in the wake of attenuation. Waves will, thus, have no negative impact after attenuation. However, plants absorb wave energy which is translated into plant movement in the course of attenuation (Paul et al. 2012). In essence, therefore, a meadow could be impacted by waves before and during attenuation. The larger and more extensive the area of attenuation is, the more likely that damage to the meadow will be important. The presence of an underlying current generated by wave asymmetry could, by bending the canopy, reduce wave attenuation (Paul et al. 2012), but there are also chances that the meadow front edge and side edges could be eroded by this underlying current (Bouma et al. 2007). Edge erosion by currents could also be important because of current channeling among vegetated patches in a meadow. Currents can thus be reduced in these interfacial areas and the shoots situated in the patches protected (Luhar and Nepf 2013). In a patchy residual meadow, currents could have important consequences on meadow destabilization because patches are generally small and each of them can be subject to erosion at its edges. Whereas currents can lead to flattening of the canopy, the effect of such flattening on wave attenuation is considered small because orbital wave motion precludes constant bending over the wave cycle (Paul et al. 2012). Plant uprooting can also occur (as reported for kelp, for instance, by Seymour et al. 1989). In a seagrass meadow, leaf loss seems also a possibility, especially where epiphytes colonize these leaves, increasing weight and reducing flexibility that can lead to breaking.

Studies are lacking regarding the influence of wind on seagrass meadow hydrodynamics and morphodynamics. These aspects can only be properly apprehended from field studies. Wind action is common in closed or semi-enclosed environments such as fetch-limited lakes, lagoons, and estuaries. Although wave transformation processes above seagrass meadows have been studied through laboratory experiments, the role winds play in modulating meadow interactions with hydrodynamics and sediment dynamics has, with very few exceptions (Bradley and Houser 2009; Paul and Amos 2011; Hansen and Reidenbach 2012, 2013), received little attention, even though wind is the main source of agitation in lakes and most fetch-limited settings. The increasing degradation of seagrass meadows worldwide also implies that the attenuation effects on hydrodynamics can be significantly impacted, thus reducing levels of coastal protection offered by these plants.

While clearly pointing out the two-way interactions between seagrass meadows and hydrodynamic, geomorphic, and sedimentary processes, the foregoing literature review also highlights a need for a better understanding of (i) wind-wave interactions 
with a seagrass meadow based on field data, (ii) wind influence in hydrodynamic interactions with a seagrass meadow, and (iii) wind-wave influence on currents and turbulence within and above a seagrass meadow. These aspects have, to our knowledge, been addressed only by Hansen and Reidenbach $(2012,2013)$ in a seagrass meadow of a species different from the one studied in this paper. Ondiviela et al. (2014) further identified a number of knowledge gaps on the role of seagrasses in coastal protection in a changing climate. These authors especially highlighted three needs: (i) field data relating plant properties and hydrodynamic conditions to enhance the geographical and ecological range of data available, (ii) a better definition of how seagrass biometric characteristics influence wave and current attenuation and sediment transport, and (iii) modeling of flow-vegetation interaction at different spatial scales, which necessitates complete datasets (hydrodynamics and vegetation characteristics) for the modeling community.

In order to contribute to a better understanding of the interactions between seagrass meadows and hydrodynamics and fulfill some of these gaps, we analyzed data acquired seasonally over a 13-month period from a Mediterranean micro-tidal and fetch-limited meadow that specifically address the following points:

(i) Wind influence on meadow hydrodynamics,

(ii) Variations in the turbulent component of currents and the influence of wind waves on this turbulent component within and above a degraded Zostera noltei meadow, and

(iii) Changes in substrate evolution and their relationship to meadow characteristics and wind-induced hydrodynamics. Our dataset should also contribute to the geographical and ecological range of data available on meadowhydrodynamic interactions.

\section{Study Site}

Berre Lagoon, one of the largest lagoons in the Mediterranean $\left(155 \mathrm{~km}^{2}\right)$, is a brackish body of water in southeastern France (Fig. 1a) bordered on the seaward side by the Nerthe hill range, and connected to the Mediterranean Sea by a natural channel, the Caronte canal (Fig. 1b). This semi-enclosed aquatic ecosystem exhibits a maximum depth of $9 \mathrm{~m}$ in its southern part. In situ measurements conducted in 2017 show that the mean tidal range in the lagoon is lower than that of the nearby Mediterranean Sea, and does not exceed $0.04 \mathrm{~m}$. Berre Lagoon is ecologically perturbed by urban and industrial pollution and by discharge from the Durance River diverted into the lagoon for hydropower generation via a canal created by Electricite de France (EDF) since 1966. This river inflow resulted in an increase in freshwater and silt inputs into the lagoon (Stora and Arnoux 1988). Prior to 1966, sediments in the deepest, southern part of the lagoon were mainly silts, whereas the shoreline sediments were sandy. Following the diversion of the river into the lagoon, a significant amount of silt accumulated, especially in the shallower northern part (Chevallier 1916; Rigaud 2011). Berre Lagoon was occupied by more than $60 \mathrm{~km}^{2}$ of Zostera marina and Z. noltei meadows at the turn of the twentieth century. Following the foregoing anthropogenic disturbances, Z. marina disappeared completely, whereas $Z$. noltei meadows regressed down to only $0.015 \mathrm{~km}^{2}$. Silt and freshwater inputs were drastically reduced, respectively, in the 1980s and 1990s. Since the 2010s, salinity has increased but still varies seasonally. It is low in winter ( 15 to $18 \%$ ), when the hydropower station is in active operation, but increases over spring to reach 25 to $28 \%$ o in summer when power needs diminish. Even though salinity has increased, $Z$. noltei has not significantly gained ground (Bernard et al. 2007). Prior to the hydropower developments that resulted in the discharge of freshwater into Berre Lagoon, $Z$. noltei was protected in part from currents and wind-wave impacts by the larger leaves of $Z$. marina. With the decrease in salinity in the lagoon and the disappearance of $Z$. marina, $Z$. noltei has become much more exposed to currents, wind waves, erosion, and accretion. This may be one of the prime causes of the reduction of this species in Berre Lagoon, and of its inability to regenerate following the initial regression under the impact of the afore-mentioned hydrological changes.

Our study was carried out at Berre Point (Fig. 1b). The meadow studied here is a patchy receding one occupying the western flank of a shallow bay (maximum depth 2 m; Fig. 2ac). Sediments are mainly composed of broken shells and sands. Carbonates represent 40 to $55 \%$ of sediments on the shoreline and 15 to $40 \%$ in front of, within, and behind, the meadow. The carbonate fraction varies seasonally: it is higher in winter than in summer. Excluding carbonates, the grain-size distribution is dominated by fine sands within and around the meadow and by fine to medium sands on the shoreline $\left(D_{50}\right.$ of sediments, excluding broken shells, ranges from 185 to $308 \mu \mathrm{m}$ in the swash zone, 112 to $150 \mu \mathrm{m}$ in the back of the meadow, 131 to $191 \mu \mathrm{m}$ within the meadow, and 175 to $185 \mu \mathrm{m}$ in front of the meadow). In the summer of 2012, the meadow occupied a total area of $1157 \mathrm{~m}^{2}$ at Berre Point. Individual patches ranged in diameter from $1 \mathrm{~m}$ for the smallest to $45 \times 20 \mathrm{~m}$ for the largest, which is itself discontinuous and composed of several sub-patches. This highly patchy character of the meadow seems to reflect its tendency to recede (Bernard et al. 2007).

The hourly mean wind directions and speeds that prevailed during all experiments were retrieved from the Marignane weather station run by Météo-France. Berre Point is located $4.5 \mathrm{~km}$ from the station and is exposed to three dominant wind directions with a fetch of $12 \mathrm{~km}$ for northwest (NW) winds, $4 \mathrm{~km}$ for southeast (SE) winds, and $8 \mathrm{~km}$ for west (W) winds (Fig. 1c). Long-term data covering the period 1949-2008 show that the lagoon is dominantly affected by NW and SE 
Fig. 1 a Berre Lagoon in southern France. b Bathymetry of the lagoon; star shows the study site. c Mean wind rose for Berre Lagoon (data from Météo France weather station in Marignane, 1949-2009)

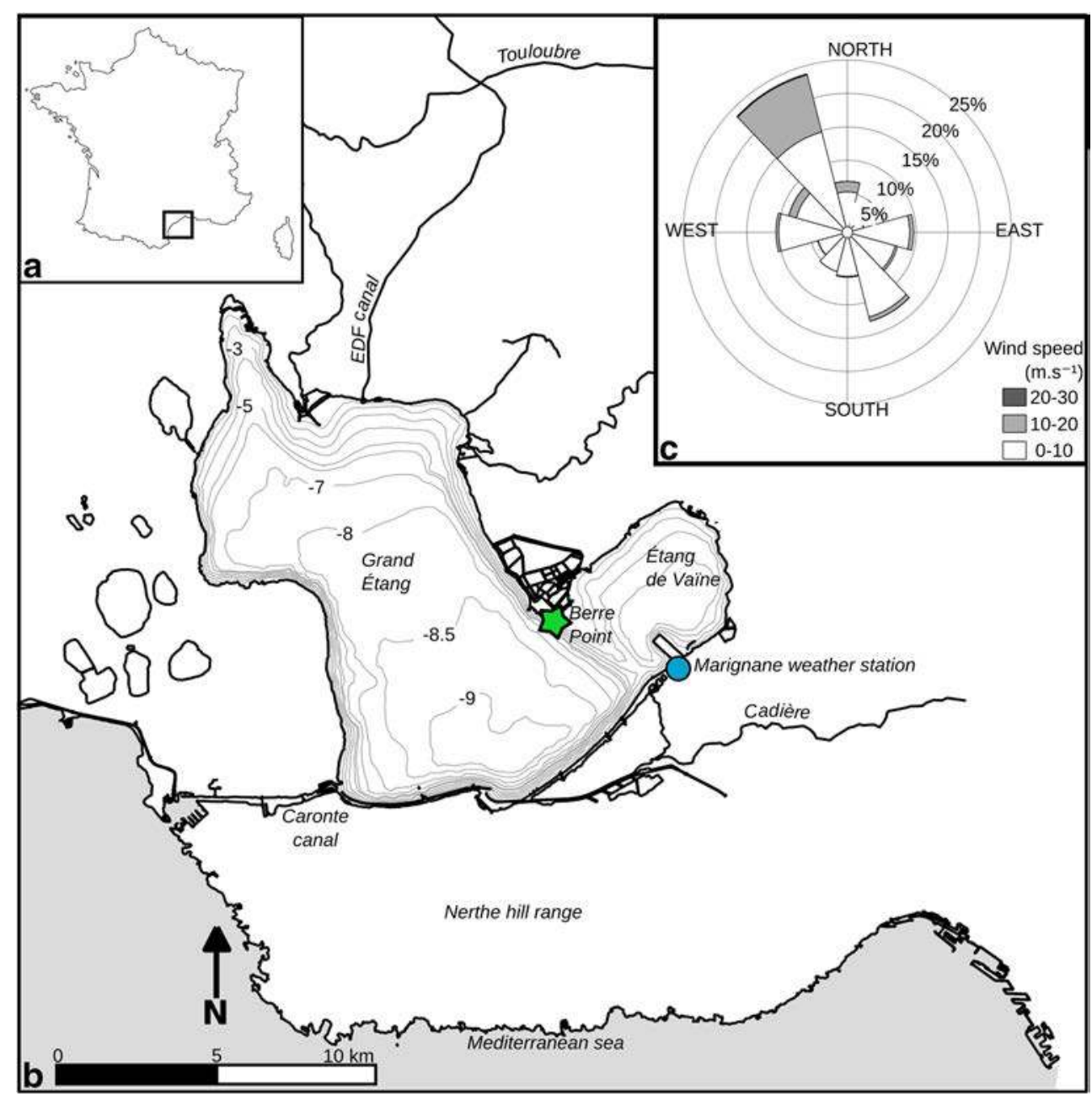

winds, the former corresponding to the famous "Mistral" wind in southeastern France. W and East (E) winds are also well represented. Strong winds (speeds $>10 \mathrm{~m} / \mathrm{s}$ ) are nearly equally distributed throughout the year but are slightly more common in winter and spring (27.6\% from January to March, $26.6 \%$ from April to June, $22.7 \%$ from July to September, and $23.1 \%$ from October to December).

\section{Methods}

\section{Wind Hydrodynamic Efficiency}

In coastal lagoons, hydrodynamic response to wind forcing is rapid and can be modified by the local geomorphology (Umgiesser et al. 2004). It is thus fair to assume that wind measurements can be used as a proxy for hydrodynamics over a long period. We used records of hourly wind directions and speeds from the Marignane weather station as a proxy for hydrodynamic forcing over the 13-month period of monitoring of meadow substrate change. We considered that wind speeds from $5 \mathrm{~m} / \mathrm{s}$ and upward are liable to generate waves and currents likely to influence the meadow substrate. We calculated the recurrence of winds exceeding $5 \mathrm{~m} / \mathrm{s}$. Each wind direction (wind directions discriminated by groups of $30^{\circ}$ starting at $15^{\circ} \mathrm{N}$ ) was considered as significantly recurrent when its value was equal to or above the median value of recurrence for all wind directions. Winds were classified into two "hydrodynamic efficiency" categories based on their direction relative to bay orientation: winds of low hydrodynamic efficiency likely generate waves that are highly refracted by the bay morphology (mostly NNW and E winds) and winds of high hydrodynamic efficiency likely generate waves that are less refracted (mostly $\mathrm{W}$ and SE winds). We identified three period categories: calm periods $(\operatorname{Re}-)$, periods with high recurrence of winds of low hydrodynamic efficiency $(\mathrm{Re}+\mathrm{LH})$, and periods with high recurrence of winds of high hydrodynamic intensity $(\mathrm{Re}+\mathrm{HH})$.

\section{Wave and Current Data Collection and Processing}

\section{Wave Characteristics}

In order to identify the different patterns of wave attenuation by the residual meadow, experiments were conducted using NKE- 
Fig. 2 Location of the current profiler during wave-current experiments (a) and pressure sensor locations and transect bathymetry in the course of wave experiments $(\mathbf{b}, \mathbf{c})$; b' sandy transect (ST), $\mathbf{b}^{\prime \prime}$ meadow transect (MT); calendar of field deployments (d)

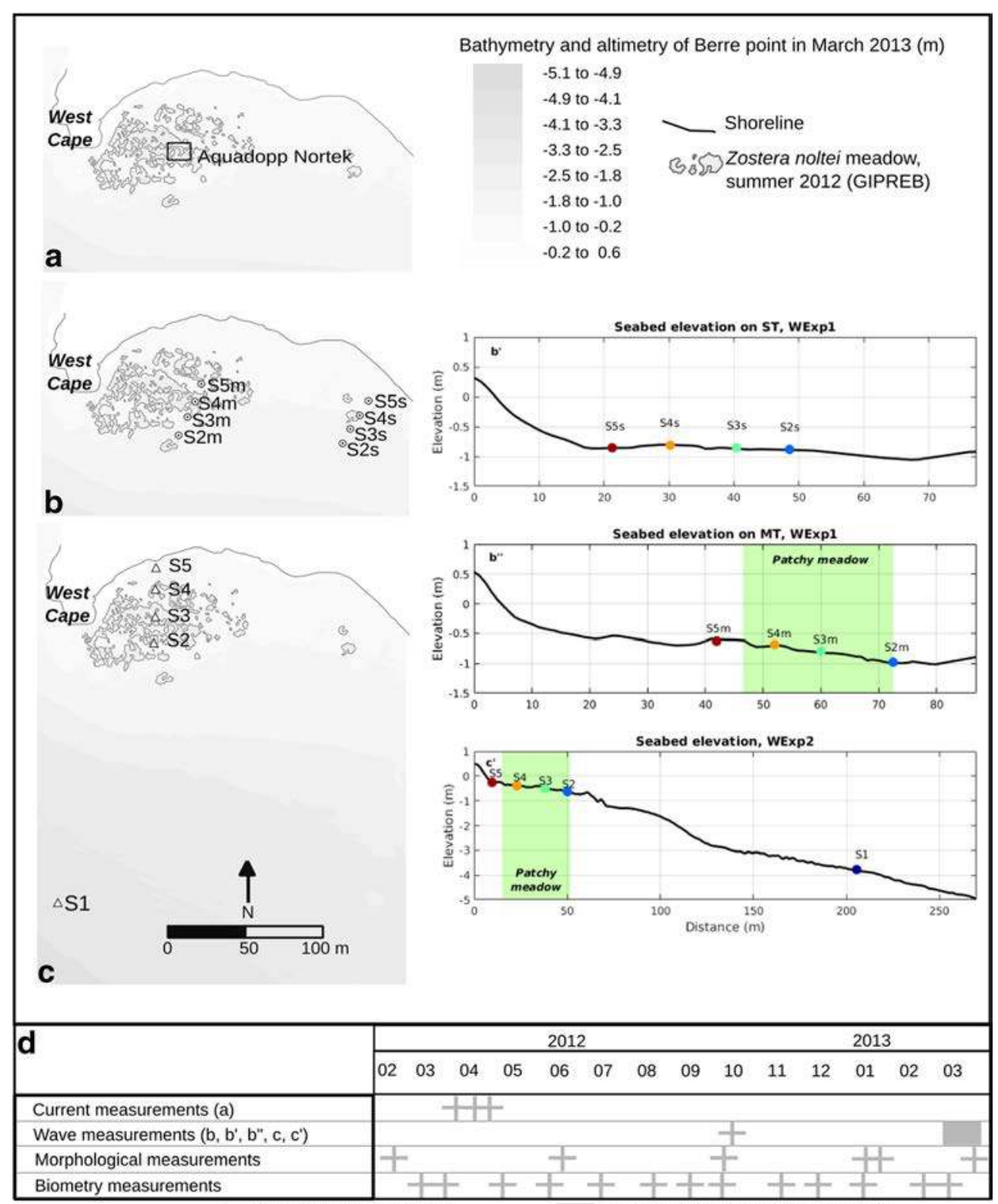

- 1 or 2 days measurements

3 weeks of continuous measurements
SP2T10m pressure sensors deployed on the bed along crossshore transects. The pressure sensor accuracy is $0.02 \mathrm{~m}$; wave heights under this value were neglected. The sensors sampled continuously at $4 \mathrm{~Hz}$. An initial experiment, wave experiment 1 (WExp1), was conducted on October 18 and 19, 2012. Eight pressure sensors were deployed along two cross-shore transects, one across the meadow, in the western part of the bay (meadow transect, named hereafter MT: sensors S2 m to S5 m; Fig. 2b, b ") and the other on the sandy bottom in the eastern part of the bay (sandy transect, hereafter named ST: sensors S2 s to S5 s; Fig. $\left.2 b, b^{\prime}\right)$. Figure $2 b^{\prime}, b^{\prime \prime}$ shows the depth of deployment of each sensor, the distance between sensors, and, for MT, the locations of sensors relative to the meadow.

To investigate the interactions of wind waves with the residual meadow, a 3 -week experiment, wave experiment 2
(WExp2), was carried out from March 9 to 28, 2013. A pressure sensor was deployed offshore (S1) and four others along a cross-shore transect in the meadow (S2 to S5; Fig. 2c, c'). The meadow front edge was situated between S2 and S3 and the back edge between S4 and S5. During WExp2, wave attenuation was monitored over four sections (Fig. 2c, c'). Section 1 extended from the offshore station (S1) to the external part of the meadow front (S2) was $153 \mathrm{~m}$ long and was devoid of vegetation (hereafter named non-vegetated offshore section). Section 2 extended from S2 to S3 was $11.5 \mathrm{~m}$ long and corresponded to the front of the meadow (meadow front edge section). Section 3, from S3 to S4, was $15 \mathrm{~m}$ long and was entirely occupied by the patchy meadow (in-meadow section). Section 4, from S4 to S5, was $12.5 \mathrm{~m}$ long and corresponded to the back edge of the meadow (meadow back edge section). 
Wave characteristics were evaluated using linear wave theory which is commonly employed for wind waves in shallow water (e.g., Lowe et al. 2007; Bradley and Houser 2009; Paul and Amos 2011). We are aware, however, that shallow water and the presence of a meadow can induce non-linearities. Wave spectra were calculated over 20-min bursts using fast Fourier transforms and a 600-s Hanning window with $75 \%$ overlapping (Sénéchal et al. 2001). All the wave spectra calculated from our dataset show a clear boundary at $0.11 \mathrm{~Hz}$ between the gravity and infra-gravity wave domains. In the zone prior to breaking (S1), a correction factor was applied, as proposed by Horikawa (1988), to account for the nonhydrostatic pressure field. This led us to adopt a $0.5-\mathrm{Hz}$ cutoff. For each burst, significant wave height $\left(H_{S}\right)$ and peak period $\left(T_{p}\right)$ were calculated in the spectral window $[0.11,0.5] \mathrm{Hz}$. Wave attenuation in vegetated settings has been characterized as an exponential decay process by Asano et al. (1988, 1992) and Kobayashi et al. (1993), and this approach has been widely employed since by other authors working in vegetated settings (Paquier et al. 2016; Anderson and Smith 2014; Coulombier et al. 2012; Möller et al. 1999, Jadhav and Chen 2012; John et al. 2016; Manca et al. 2012). The exponential decay rate is expressed as follows:

$\mathrm{H}_{1}=\mathrm{H}_{0} e^{-K_{i} x}$

where $H_{0}$ is the significant wave height at the first station, $H_{1}$ is the significant wave height at the second station, $x$ is the distance between the stations, and $K_{i}$ is the wave height decay rate.

\section{Current Velocities and Directions}

Measurements of current velocities and directions were recorded in the course of three wind events in spring 2012 (April 8, 2012: wave-current experiment 1 (WCExp1); April 18, 2012: wave-current experiment 2 (WCExp2); April 25 and 26, 2012: wave-current experiment 3 (WCExp3)). A current profiler (Aquapro HD Nortek) was deployed in the meadow, in a down-looking position at $0.70 \mathrm{~m}$ from the bed in a small non-vegetated patch to avoid disturbance by leaves (Fig. 2a). Currents were measured from the bed to $0.6 \mathrm{~m}$ above the bed in bins of $0.03 \mathrm{~m}$ at a rate of $4 \mathrm{~Hz}$ over bursts of $2048 \mathrm{~s}$. We discarded the data closest to the bed (from 0 to $0.065 \mathrm{~m}$ ) as such data can potentially be contaminated by side-lobe interference. Mean current directions were averaged for each vertical bin over $64 \mathrm{~s}$.

The current profiler also measured water pressure. Currents and pressure were measured at the same rate. For each burst, significant wave heights $\left(H_{s}\right)$ and peak periods $\left(T_{p}\right)$ were calculated using linear wave theory (see details of the method in the "Wave Characteristics" section wave characteristics). These measurements were used to (i) describe the vertical distribution of currents and turbulence in the meadow and (ii) investigate the dominant processes involved in the interactions of currents with a residual meadow in the fetch-limited setting of Berre Lagoon.

The Reynolds number ( $\mathrm{Re}$ ) was first calculated to evaluate the flow regime, using the following equation:

$\operatorname{Re}=\frac{\rho . V \cdot h}{\mu}$

where $\rho$ is the water density in $\mathrm{kg} / \mathrm{m}^{2}, V$ is the mean depthintegrated current velocity in $\mathrm{m} / \mathrm{s}, h$ is the characteristic length of turbulence (considered as the depth of the water column in $\mathrm{m}$ in shallow water), and $\mu$ is the dynamic viscosity of seawater in $\mathrm{Pa} / \mathrm{s}$.

During the field measurements, the Reynolds Number ranged from 2700 to 11,400 , indicating that the flow regime was turbulent throughout all moderate and strong wind conditions. Current velocity can be decomposed as $u=U+u^{\prime}$, where $u$ is the instantaneous current velocity, $U$ is the timeaveraged current velocity, and $u^{\prime}$ is the turbulence. In settings dominated by currents, the turbulent kinetic energy (TKE) is calculated from the instantaneous current velocity (Neumeier 2007; Coulombier et al. 2012) using the following equation:

$\mathrm{TKE}=\frac{1}{2}\left(u^{\prime 2}+v^{\prime 2}+w^{\prime 2}\right)$

where $u^{\prime}, v^{\prime}$, and $w^{\prime}$ are the turbulence associated with the three components of instantaneous current velocity. In a fetchlimited setting, wind waves can contribute significantly to turbulence associated with currents; it is thus necessary to use the method developed by Soulsby and Humphery (1990) to isolate the wave contamination effect on current turbulence.

Soulsby and Humphery (1990) calculated TKE with effects of waves removed. They used a graphic method that consisted in the delimitation of a peak corresponding to wave energy from the current spectra. This peak is determined from the turbulence spectra using the frequency range of wave occurrence. It is thus possible to separate the waveinduced contamination $\left(u_{w}^{\prime}, v_{w}^{\prime}, w^{\prime}{ }_{w}\right)$ from turbulence $\left(u_{t}^{\prime}\right.$, $\left.v_{t}^{\prime}, w_{t}^{\prime}\right)$. Stapelton and Huntley (1995) proposed a spectral method to identify the wave-induced contamination. We modified the Stapelton and Huntley (1995) algorithm in order to extract automatically wave-induced contamination between the sub-harmonics $2 f_{1}$ and $1 / 2 f_{1}$, where $f_{1}$ is the first harmonic. When the spectrum is plotted on log-log axes, wave-induced contamination can be separated by a straight line (Soulsby and Humphery 1990). In order to evaluate TKE, the energy spectra were calculated for each component of turbulence $\left(u^{\prime}, v^{\prime}, w^{\prime}\right)$ on the 8192 samples of each burst using fast Fourier transforms (FFT), wave-induced contamination was removed, spectra without wave-induced contamination were integrated, and TKE was calculated. 


\section{Meadow Biometry}

From March 01, 2012 to March 12, 2013, measurements of meadow biometry were conducted once a month at Berre Point. Shoot density was measured at 20 stations randomly chosen using a $0.2 \times 0.2-\mathrm{m}$ quadrat. Five leaf lengths were measured at each station. Due to low water temperatures $(<$ $5{ }^{\circ} \mathrm{C}$ ), and a sparse winter meadow, the number of measured stations was reduced during two winter visits (18 stations in February 2012 and 11 stations in January 2013). Meadow mapping was conducted each summer by aerial photograph analysis and validated by field surveys.

\section{Substrate Changes in the Meadow and Adjacent Non-Vegetated Bed}

Six topographic surveys were carried out on foot using a RTK DGPS between February 2012 and March 2013, including within the meadow. Cross-shore and long-shore transects were set up every 10 to $15 \mathrm{~m}$, and supplementary measurements were carried out on specific forms (mat, shoreline). The surveys were referenced relative to NGF (French national geodetic reference, corresponding to the mean sea level). One-meter cell digital elevation models (DEMs) were computed from the data using the Delaunay triangulation method. The DEMs highlighted patterns of evolution of the substrate and adjacent non-vegetated seabed. DGPS field measurements are likely to be subject to some level of uncertainty. In the analysis of the DEMs, the expected error was considered to be $\pm 0.1 \mathrm{~m}$.

\section{Results}

\section{Meadow Biometry}

Field observations show that the patchy meadow had an elevation of 0.1 to $0.4 \mathrm{~m}$ relative to the surrounding nonvegetated bed and a "mat"-like morphology similar to that of Posidonia oceanica meadows (Boudouresque et al. 2016). During the year 2012-2013, shoot density increased in spring, was high in summer, decreased in autumn, and was low in winter (Fig. 3). Auby and Labourg (1996) observed a similar pattern of shoot-density evolution in Arcachon Lagoon on the Atlantic coast of France. At Berre Point, leaf-length evolution in the course of the year exhibited the same seasonal pattern as that of shoot density. This pattern is unusual. Auby and Labourg (1996) observed maximum shoot lengths in late summer and autumn due to the formation of new shoots and shedding of larger and older shoots. The specific pattern of leaf-length evolution observed in Berre Lagoon could reflect the low productivity of this residual meadow.
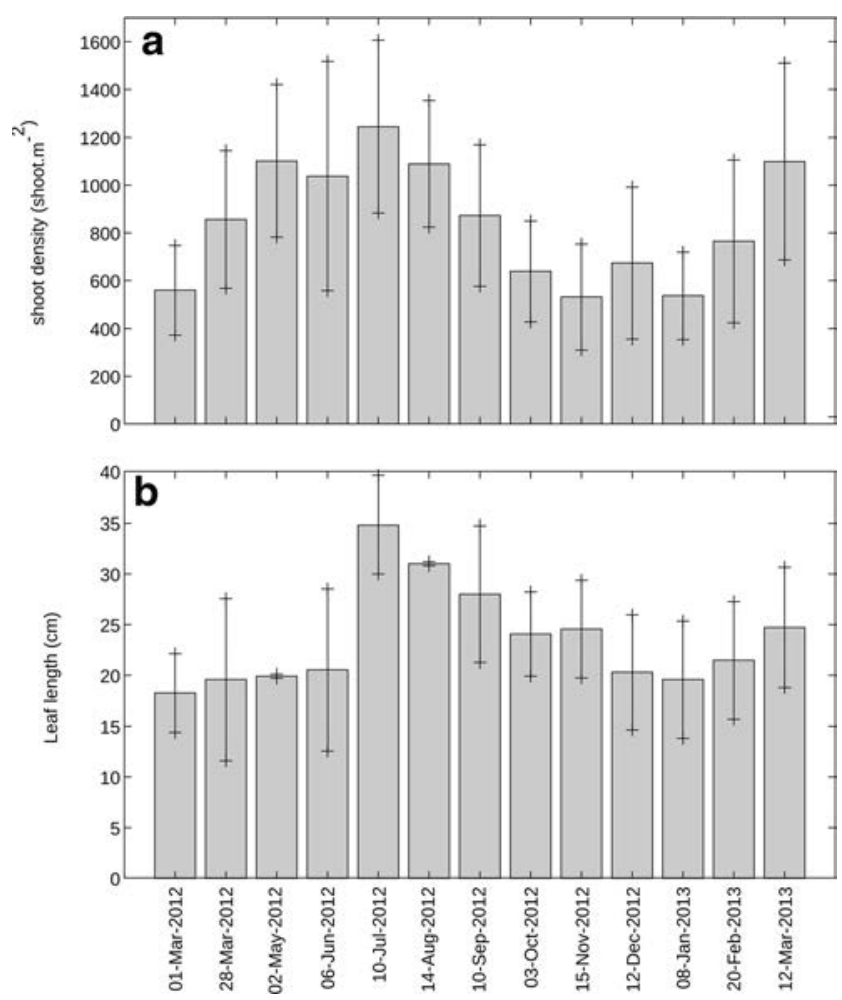

Fig. 3 Mean shoot density (a) and leaf length (b) at Berre Point between March 2012 and March 2013. Standard errors are represented by black crosses

\section{Hydrodynamics}

\section{Wave Attenuation Across the Meadow}

WExp1, conducted during a SE wind event, enables a comparison of wind-wave patterns over the sandy transect (ST) and over the meadow (MT), highlighting the impact of the latter on wave attenuation. This event, monitored over a period of $19 \mathrm{~h}$, was characterized by two wind peaks of 10.9 and $10.6 \mathrm{~m} / \mathrm{s}$ (Fig. 4a). The highest $H_{s}$ were recorded from 13:00 to 14:30. $T_{p}$ was constant along the transect ST, whereas $H_{S}$ decreased slightly between S2 and S3 s, over the meadow front, increased at S4 s before decreasing once again at S5 s (Fig. 4c). These changes were mirrored by the wave attenuation pattern (Fig. 4g). Along ST, a slight set-down occurred from S2 to S5 s in the course of the event while $H_{s}$ decreased (Fig. 4e). Over MT, both $H_{s}$ (Fig. 4d) and wave attenuation (Fig. 4h) showed marked fluctuations but the pattern differed from that of ST. Over MT, a slight setup was observed while $H_{s}$ decreased (Fig. 4f).

WExp2 coincided with nine wind events that generated $H_{s}$ values $>0.3 \mathrm{~m}$ at S1. Events 2, 5, 7, and 8 were associated with NW winds ( 300 to $360^{\circ} \mathrm{N}$ ). Event 2 was the longest and strongest. It lasted $63 \mathrm{~h}$, had a wind peak speed of $22.9 \mathrm{~m} / \mathrm{s}$ (Fig. 5a), and the maximum wave height at $\mathrm{S} 1$ reached $1.2 \mathrm{~m}$ with a $T_{p}$ value of $5.5 \mathrm{~s}$ (Fig. 5b). Events 3, 6, and 9 were generated by SE winds $\left(80\right.$ to $\left.130^{\circ} \mathrm{N}\right)$. Event 3 had a high peak 


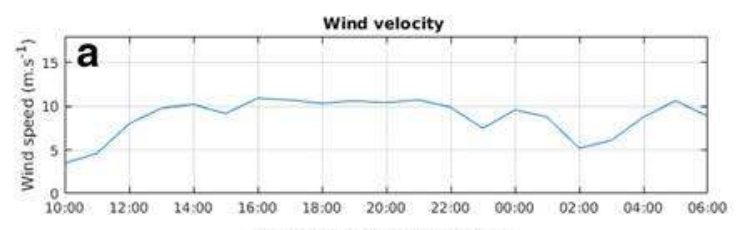

Significant wave height - ST

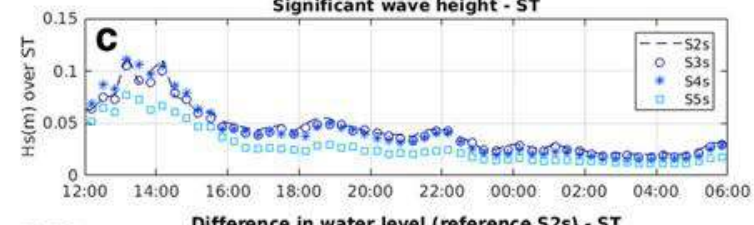

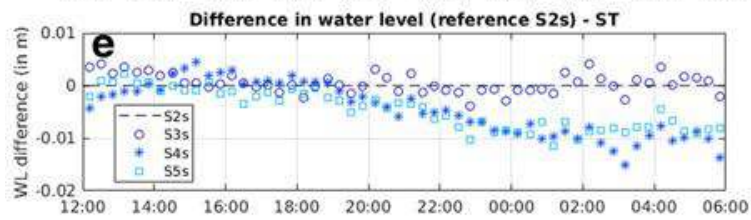

Exponential wave decay rate - ST

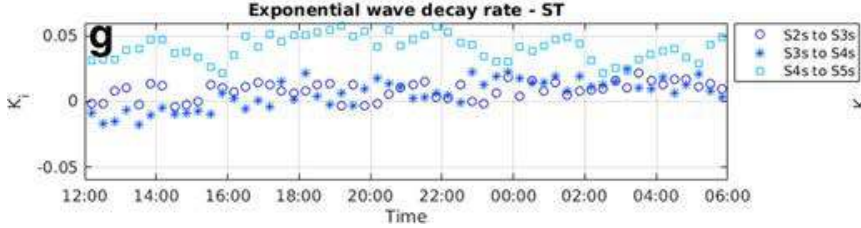

Fig. 4 Wind and hydrodynamic conditions during wave experiment 1 (WExp1) in October 2012. a Wind speed $(\mathrm{m} / \mathrm{s})$ and $\mathbf{b}$ wind direction $\left({ }^{\circ} \mathrm{N}\right)$. c Significant wave height over ST (S2 s = most offshore station and S5 s=most inshore). d Significant wave height over MT (S2 m =

wind speed $(13.8 \mathrm{~m} / \mathrm{s} ;$ Fig. $5 \mathrm{a})$ associated with a $H_{s}$ of $0.53 \mathrm{~m}$ at $\mathrm{S} 1$ and $T_{p}$ of $2.6 \mathrm{~s}$ (Fig. 5b). Events 1 and 4 were generated by $\mathrm{W}$ winds. Event 4 was also remarkable with a peak wind
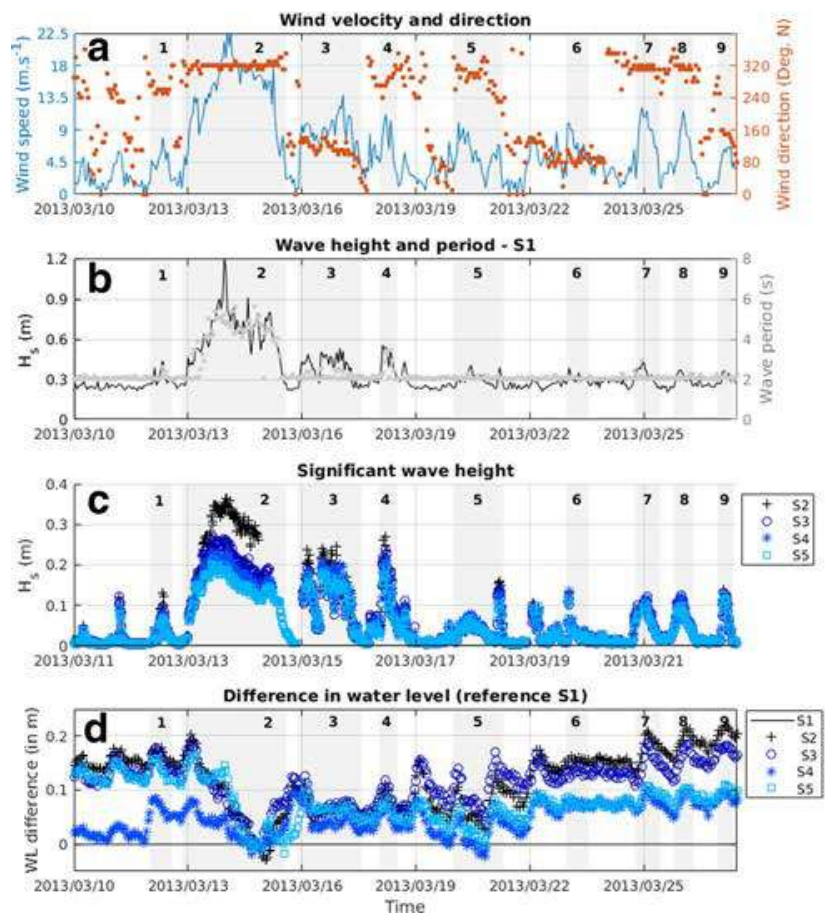

Fig. 5 Wind and hydrodynamic conditions monitored during wave experiment 2 (WExp2) in March 2013. a Wind speed $(\mathrm{m} / \mathrm{s})$ and wind direction $\left({ }^{\circ} \mathrm{N}\right)$. b Significant wave height and peak period at S1. c Significant wave
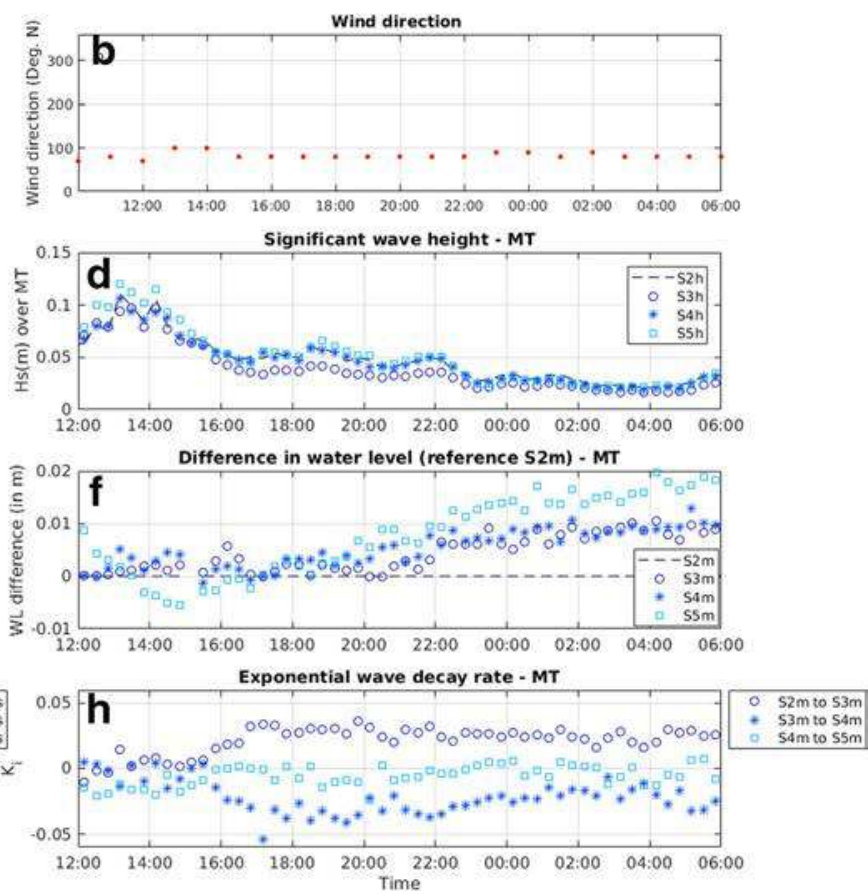

most offshore station and S5 $\mathrm{m}=$ most inshore). e Difference in water level in reference to S2 s over ST. f Difference in water level in reference to S2 m over MT. g Exponential wave decay rate over ST. h Exponential wave decay rate over MT

speed of $11.2 \mathrm{~m} / \mathrm{s}$ (Fig. $5 \mathrm{a}$ ), a peak storm $H_{s}$ value of $0.55 \mathrm{~m}$ at $\mathrm{S} 1$, and a $T_{p}$ of $3.5 \mathrm{~s}$ (Fig. $5 \mathrm{~b}$ ). Figure 5 shows the wind and wave parameters during these events.
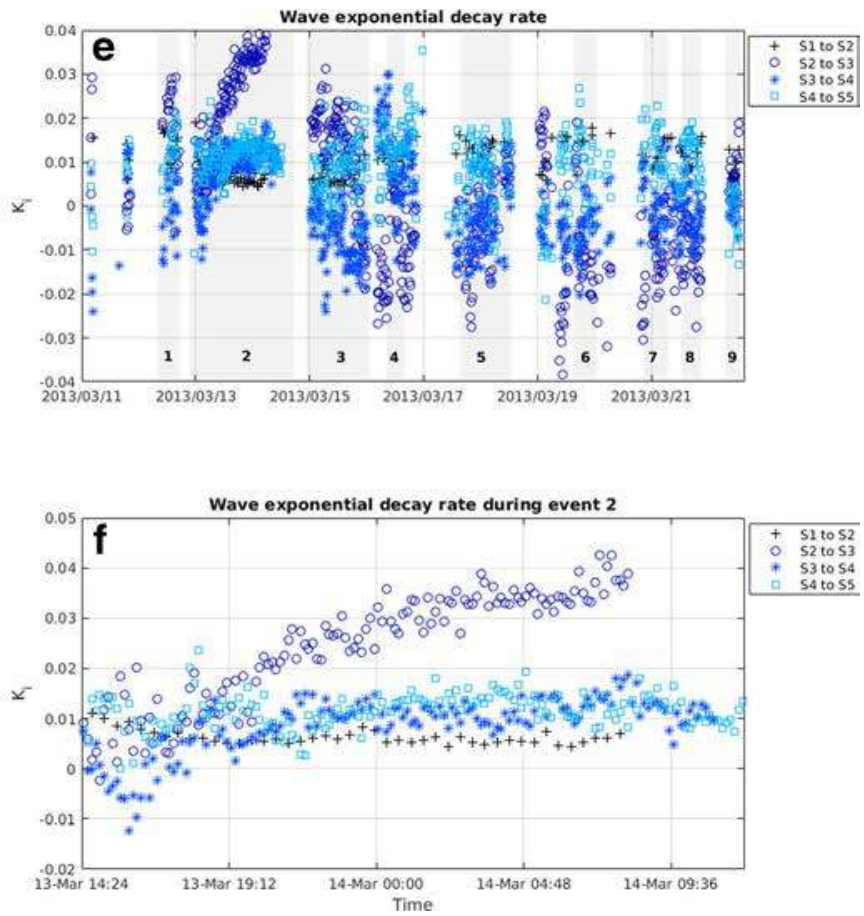

height over the transect ( $\mathrm{S} 1=$ most offshore station and S5 = most inshore). d Still water level over the transect. e Exponential wave decay rate over the transect. f Focus on wave attenuation patterns during event 2 
The analysis of wind and wave characteristics along the cross-shore transect brought out four wave attenuation patterns defined on the basis of ranges of five wind speed and three directions (Table 1). Pattern 1 corresponded to $H_{S}<0.35 \mathrm{~m}$ with periods of 2 to $2.4 \mathrm{~s}$ offshore (at S1) and wave attenuation rates close to zero throughout the transect, thus signifying that interaction between wind waves and the meadow was negligible. This pattern of wave attenuation was observed with NW and SE wind speeds $<8 \mathrm{~m} / \mathrm{s}$ and $\mathrm{W}$ wind speeds $<5 \mathrm{~m} / \mathrm{s}$ (events 1 and 9; Fig. 5). Pattern 2 was characterized by maximum $H_{s}$ values of $0.42 \mathrm{~m}$, periods of 2 to $3.3 \mathrm{~s}$, and moderate attenuation rates above the middle of the meadow and its back edge. This pattern corresponded to NW wind speeds ranging from 8 to $11 \mathrm{~m} / \mathrm{s}$ (events 5, 7, and 8; Fig. 5) and $\mathrm{W}$ wind speeds of 5 to $8 \mathrm{~m} / \mathrm{s}$ (event 1; Fig. 5). Pattern 3 was observed at the front and back edges of the meadow for waves attaining $H_{s}$ of $0.5 \mathrm{~m}$ and periods of 2 to $4.5 \mathrm{~s}$ offshore. The effect of the front edge of the meadow was stronger than that of the back edge. This pattern was observed when NW wind speeds ranged from 11 to $14 \mathrm{~m} / \mathrm{s}$ (phase 1 of storm growth in the course of event 2 in Fig. 5), and SE wind speeds from 8 to $14 \mathrm{~m} / \mathrm{s}$ (events 3 and 6; Fig. 5). Pattern 4 was one of strong wave attenuation rates throughout the transect, and prevailed when NW wind speeds were between 14 and $22 \mathrm{~m} / \mathrm{s}$ (phase 2 of event 2; Fig. 5) and W wind speeds between 8 and $11 \mathrm{~m} / \mathrm{s}$ (event 4; Fig. 5). Under these strong wind-forcing conditions, $H_{s}$ attained, respectively, maxima of 1.2 and $0.56 \mathrm{~m}$ and periods of 3 to $4.6 \mathrm{~s}$, and the waves were progressively dissipated by the meadow without breaking, in a manner similar to that described for extremely dissipative muddy coasts (Gratiot et al. 2007; Winterwerp et al. 2007).

During WExp2, wave attenuation was monitored over four sections (see Fig. 2c, c'). The characteristics of these sections were described in the "Wave Characteristics" section. Wave refraction can occur over the non-vegetated off-shore section (from S1 to S2) due to the lagoon morphology. NW wind waves and $\mathrm{W}$ wind waves are strongly refracted offshore and around

Table 1 Wave heights $\left(H_{S}\right)$ and periods $\left(T_{p}\right)$ offshore at S1 spatial pattern of wave attenuation during the March 2013 survey

\begin{tabular}{llll}
\hline $\begin{array}{l}\text { Wind speed } \\
(\mathrm{m} / \mathrm{s})\end{array}$ & NW wind & SE wind & W wind \\
\hline$[0,5]$ & - & - & $0.28 \mathrm{~m}-2.1 \mathrm{~s}^{*}$ \\
{$[5,8]$} & $0.26 \mathrm{~m}-2 \mathrm{~s}^{*}$ & $0.35 \mathrm{~m}-2 \mathrm{~s}^{*}$ & $0.42 \mathrm{~m}-2.6 \mathrm{~s} *$ \\
{$[8,11]$} & $0.42 \mathrm{~m}-2 \mathrm{~s}^{* *}$ & $0.38 \mathrm{~m}-2.1 \mathrm{~s} * * *$ & $0.56 \mathrm{~m}-2.3 \mathrm{~s}^{* * * *}$ \\
{$[11,14]$} & $0.5 \mathrm{~m}-2.49 \mathrm{~s}^{* * *}$ & $0.53 \mathrm{~m}-2.5 \mathrm{~s} * * *$ & - \\
{$[14,22]$} & $1.2 \mathrm{~m}-5.2 \mathrm{~s}^{* * * *}-$ & - \\
\hline
\end{tabular}

*pattern 1, wave attenuation rates close to zero; **pattern 2, attenuation above the middle zone and back edge of the meadow; ***pattern 3 , important attenuation above the front and back edges of the meadow; ****panel: pattern 4 , attenuation all along the transect, important attenuation above the meadow front edge. Values in the table corresponds to $H_{s}$ and $T_{p}$ for events representing the patterns the West Cape of Berre lagoon (Fig. 2) while SE wind waves are not refracted. However, over the three other sections (from S2 to S5), and according to field observations, the direction of wave propagation is parallel to the transects. In order to understand wave attenuation over a degraded meadow, the exponential wave decay rate $\left(K_{i}\right)$ for each section was compared with normalized water depth and wave period $(T)$ as a function of the significant wave height $\left(H_{S}\right)$ at the first station of the section considered (Figs. 6 and 7). While patterns are identifiable for the data monitored during NW wind events, there is no specific trend during SE and $\mathrm{W}$ events due to limited recorded data. We will thus focus on the results concerning NW wind events.

Over section 1, the non-vegetated section, the values of $K_{i}$ were generally lower than those calculated over the vegetated sections (maximum of 0.02 against 0.04 on the $\mathrm{S} 2-\mathrm{S} 3$ section) but were always positive (no shoaling). Wave attenuation tended to increase slightly with water depth (and thus with water level) and to decrease with wave period and height. On the other vegetated sections, $K_{i}$ values were either positive (wave attenuation) or negative (shoaling). The most extremes values were monitored over section $\mathrm{S} 2-\mathrm{S} 3$, the meadow front (from -0.03 to 0.04 ), followed by more shoreward sections (maximum of 0.02 on S3-S4 and S4-S5). Over the meadow front, $K_{i}$ values tended to increase with wave height and wave period and to decrease with water depth (thus, with water level). These trends were less marked over the in-meadow section (S3-S4) and the meadow back edge section (S4-S5).

\section{Current and Wave Interactions Within the Meadow}

Currents and waves were measured within the residual meadow under different wind conditions: WCExp1 was conducted during a strong $(17.8 \mathrm{~m} / \mathrm{s}) \mathrm{NW}$ wind event, WCExp2 over the course of a W wind event characterized by two phases (phase 1: WNW winds of up to $5.2 \mathrm{~m} / \mathrm{s}$; phase 2: WSW winds of up to $7.3 \mathrm{~m} / \mathrm{s}$ ), and WCExp3 during SE winds of up to $12.8 \mathrm{~m} / \mathrm{s}$ ). The results of these experiments, shown in Fig. 8, highlight variable currents and TKE in the water column that reflect a strong influence of the meadow besides wind influence at the water surface.

Figure 9 synthesizes the results and describes the vertical profile for each wind condition and the superposition of several layers involving non-linear processes in complex interaction. We recall that the data were collected from the upper midwater column to the bottom layer. In shallow water, part of the momentum of the wind is transferred to the water surface through wind shear stress. This process generated a winddriven current layer (WiDCL in Fig. 9). The WiDCL was identified here as the upper mid-water column. Our results showed a rapid response of this layer to strong winds via their influence, in this fetch-limited setting, on wave heights, current speed and direction, and TKE (in agreement with the changes observed in the course of WCExp2; Fig. 8b, b', b', b'"). TKE and its vertical penetration increased with wind speed, but they also depended 

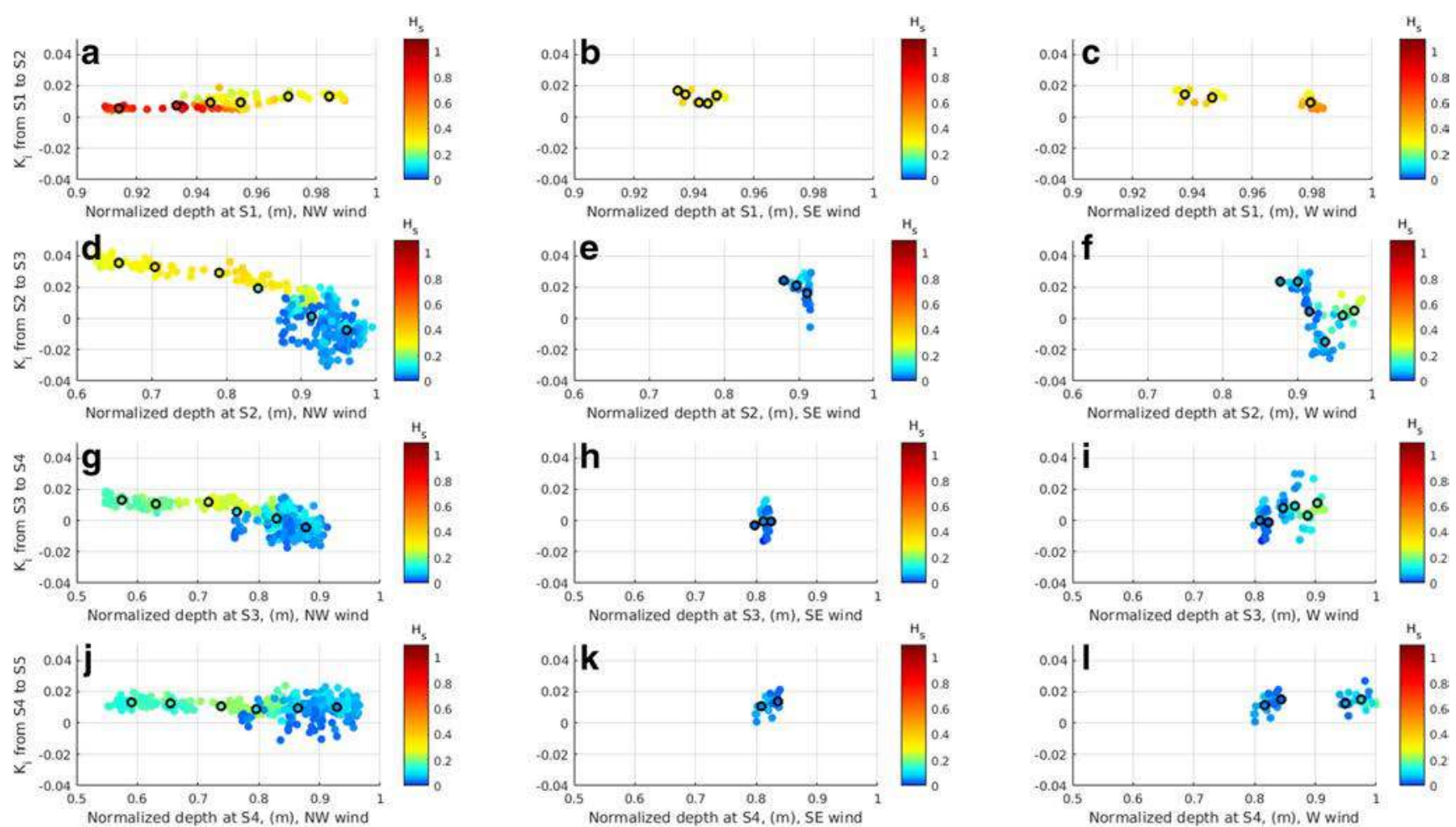

Fig. 6 Comparison of exponential wave decay rate $\left(K_{i}\right.$ in $\left.\mathrm{m}\right)$, water depth normalized (in $\mathrm{m}$, on 3.4 for S1, 1 for S2 and S3, and 0.7 for S4), and significant wave height $\left(H_{s}\right.$ in $\left.\mathrm{m}\right)$ at the first station of each section (see the "Methods" section for description). Graphs depict scatter plots

showing the relationship of $K_{i}$ over each section with water depth (S1S2: first line, S2-S3: second line, S3-S4: third line, S4-S5: fourth line) for each wind direction (NW: first column, SE: second column, W: third column)
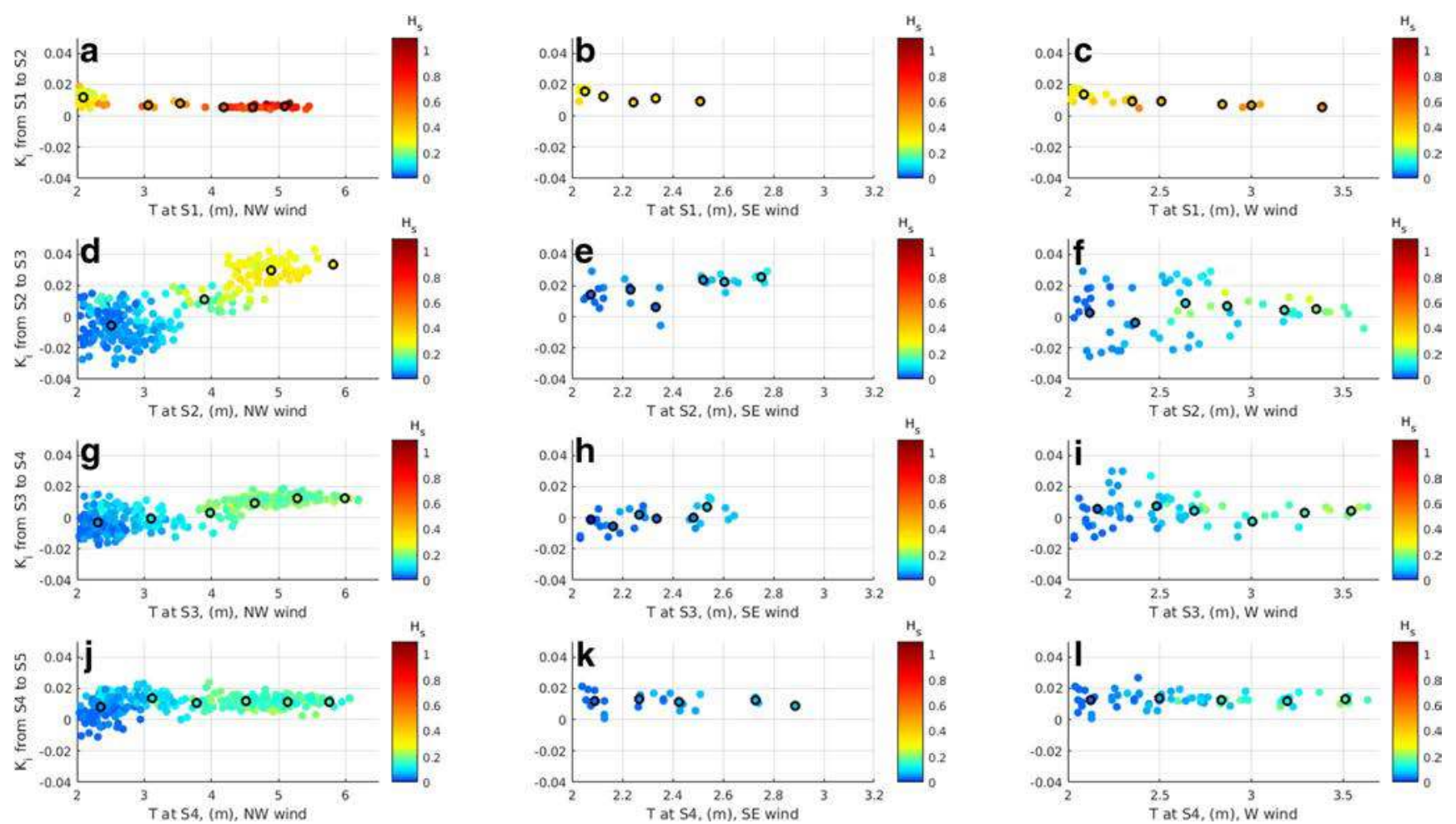

Fig. 7 Comparison of exponential wave decay rate ( $K_{i}$ in m), wave periods (in s), and significant wave height $\left(H_{s}\right.$ in $\mathrm{m}$ ) at the first station of each section (see the "Methods" section for description). Graphs depict scatter plots

showing the relationship of $K_{i}$ over each section with wave period (S1-S2: first line, S2-S3: second line, S3-S4: third line, S4-S5: fourth line) for each wind direction (NW: first column, SE: second column, W: third column) 

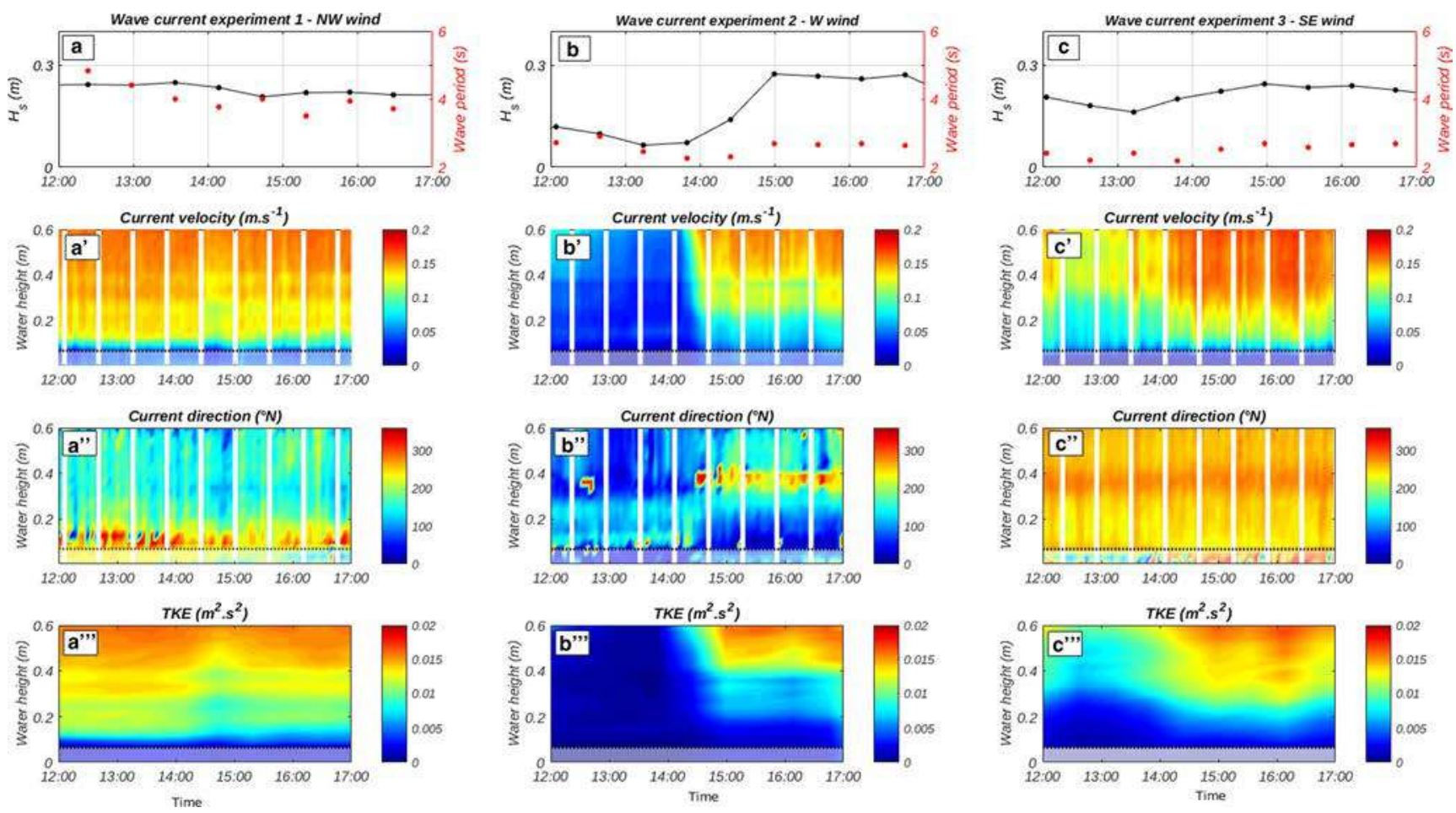

Fig. 8 Wave conditions $(\mathbf{a}-\mathbf{c})$, current velocities averaged on $1024 \mathrm{~s}\left(\mathbf{a}^{\prime}-\mathbf{c}^{\prime}\right)$, current directions averaged on $1024 \mathrm{~s}\left(\mathbf{a}^{\prime \prime}-\mathbf{c}^{\prime \prime}\right)$, and turbulent kinetic energy (a '"'-c'") in the seagrass meadow at Berre Point during wave-current experiments 1 (WCExp1), 2 (WCExp2), and 3 (WCExp3). On each 3D plot, the whitened

section close to the bed corresponds to the data potentially not valid considering the side-lobe interference generated by the method of measurement. These data are shown for transparency but are not considered in the presentation of the results or in their interpretation

on wind direction. For instance, a moderate SE wind event (WCExp3; Fig. 9d) generated the same TKE in the upper mid-water column as a strong Mistral event (WCExp1; Fig. 9a). The flow direction should be consistent with the prevailing wind direction, which was the case during WCExp3 (Fig. 8c"). In contrast, when the wind blew from WSW (WCExp2 - phase 2), the resulting current headed SSE (Figs. 8b" and 9c). We identified a morphological control on wave height caused by refraction offshore ("Meadow Patchiness and Erosion and Sedimentation" section), and we hypothesize that the WiDCL was in strong interaction with waves and with a wave-induced current layer (WICL). The WiDCL was diverted and its direction became strongly divergent relative to the prevailing wind direction. Under NW (WCExp1) and WNW winds (WCExp2 - phase 1), the WiDCL direction deviated slightly relative to the wind direction (Fig. 9a, b). These intermediate cases could be due to strong winds influencing the WiDCL.

A wave-induced interaction current layer (WiDWICL), shown in Fig. 9, is a hypothetic zone where wind-driven processes may strongly interact with a wave-induced current, which increases shear stress and then TKE (as shown by the data in Fig. 8a"'). Under the WiDCL, current velocities were still strong and a second peak of strong TKE occurred during WCExp1, as shown in Fig. 9a. During WCExp2 - phase 1, waves were negligible and did not generate currents within the WiDWICL (Fig. 9b). During WCExp2 - phase 2, and WCExp3, this layer was either non- existent or merged with the WiDCL (Fig. 9c, d). Above this WiDWICL, the current was strongly dominated by wind processes. Inside the WiDWICL, wave orbital velocities may contribute to the overall current. The role of wave orbital velocities during WCExp1 is supported by the data since, during this survey, wave height was similar to what was observed during WCExp2 - phase 2 and WCExp3, but wave period was higher (4 $\mathrm{s}$ against approximately 2.5 during other events; Fig. 8a-c). As waves with higher periods are better attenuated by vegetation than short waves (e.g., Lowe et al. 2007; Koftis et al. 2013; Manca et al. 2012; Paul and Amos 2011; Hansen and Reidenbach 2013), we expect the attenuation of waves to generate a turbulent current flow above the meadow as energy is dissipated. The WiDWICL could correspond to this energy dissipation.

The water column was characterized by low current velocity, low TKE, and unstable flow direction during WCExp1 above the layer potentially contaminated by side-lobe interference (between 0.065 and $0.15 \mathrm{~m}$ ). The results from WCExp2 and WCExp3 do not enable us to infer the existence of this layer (Fig. 8).

\section{Morphodynamics of the Residual Meadow and Adjacent Non-Vegetated Area}

The evolution of the bed morphology was observed at different timescales: over a year, seasonally, and over a period of a few weeks. The results show that the range of bed evolution 


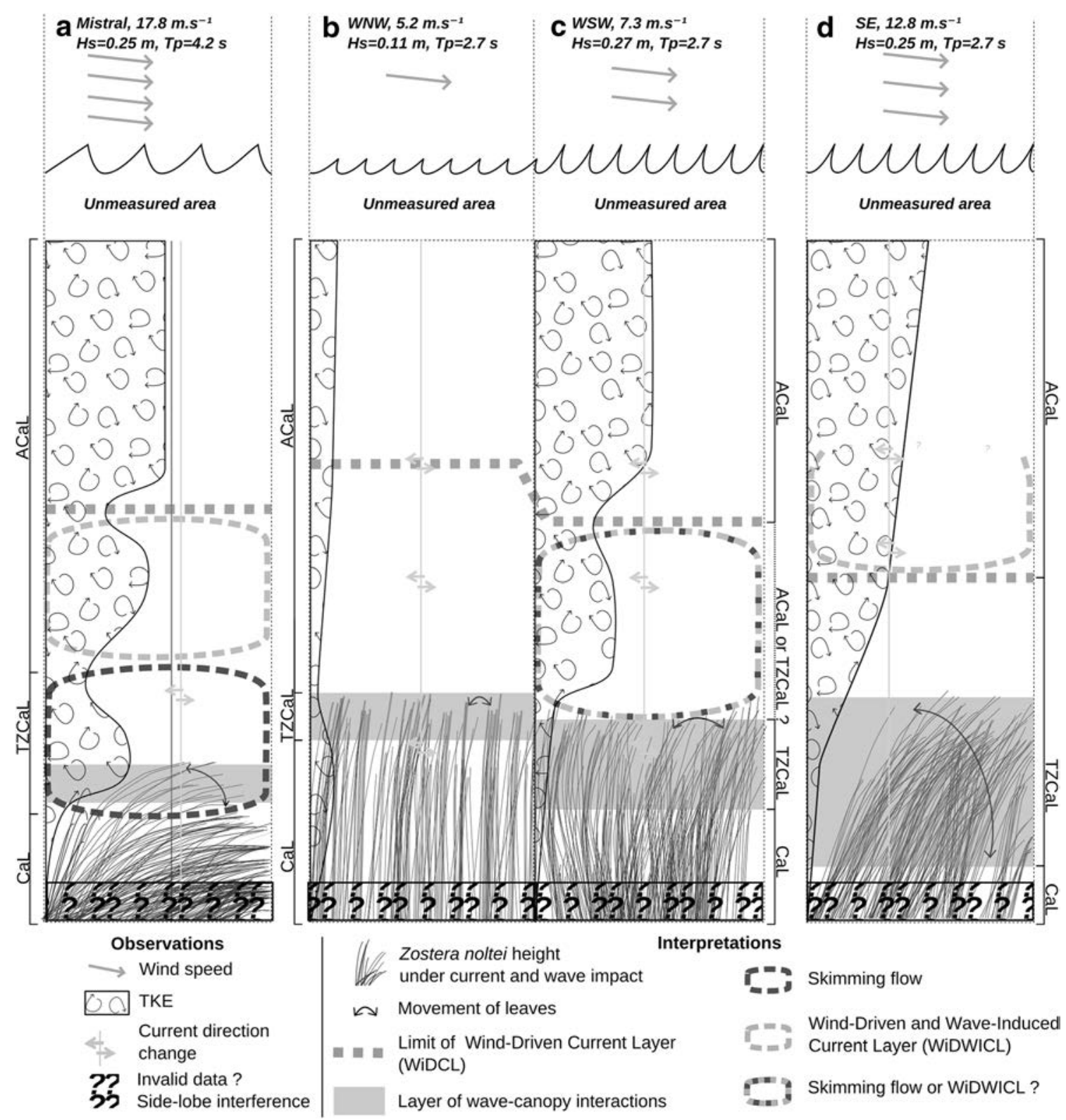

Fig. 9 Summary of processes associated with currents in the seagrass meadow of Berre Point under four wind conditions corresponding to wave-current experiments (WCExp 1 to 3 )

can be of the same order over these different timescales (Fig. 10). At the annual scale, from February 23, 2012 to January 22,2013 , even though the emerged beach was characterized by an alternation of mild erosion and accretion $(-0.5$ to + $0.5 \mathrm{~m}$ ), no bed substrate evolution was observed within and outside the meadow (Fig. 10a), although winds of high morphogenic efficiency were very frequent.

At the seasonal scale, the meadow substrate, like the subaerial beach, showed significant variability. From late winter to early summer (February 23 to June 8, 2012; Fig. 10b), the beach showed an alternation of noteworthy erosion and accretion $(-0.7$ to $+0.7 \mathrm{~m})$ and the meadow substrate was slightly eroded $(0.1$ to $0.3 \mathrm{~m})$. Over the same period, winds of high morphogenic efficiency were strongly recurrent. Slight but expansive accretion of the substrate within and outside the meadow, and of the beach, was monitored during summer and early autumn (June 9 to October 3, 2012; Fig. 10c). During this period, winds were generally weak. During autumn and the early winter (October 4, 2012 to January 22, 2013), stability was observed on the bed, whereas the beach showed anew an alternation of erosion and accretion (Fig. 10d). This period was characterized by a high recurrence of winds of low morphogenic efficiency. During the second winter (January 23 to March 21, 2013), we measured an extensive swathe of minor erosion on the non-vegetated bed, minor erosion in front of the meadow, slight accretion between the meadow and the beach, and mild accretion of the beach in the back of the meadow (Fig. 10e). A high recurrence of winds of low morphogenic 
Fig. 10 Annual, seasonal, and short-term topographic and bathymetric changes observed in the seagrass meadow at Berre Point between February 2012 and March 2013. The margin error is evaluated at $\pm 10 \mathrm{~cm}$

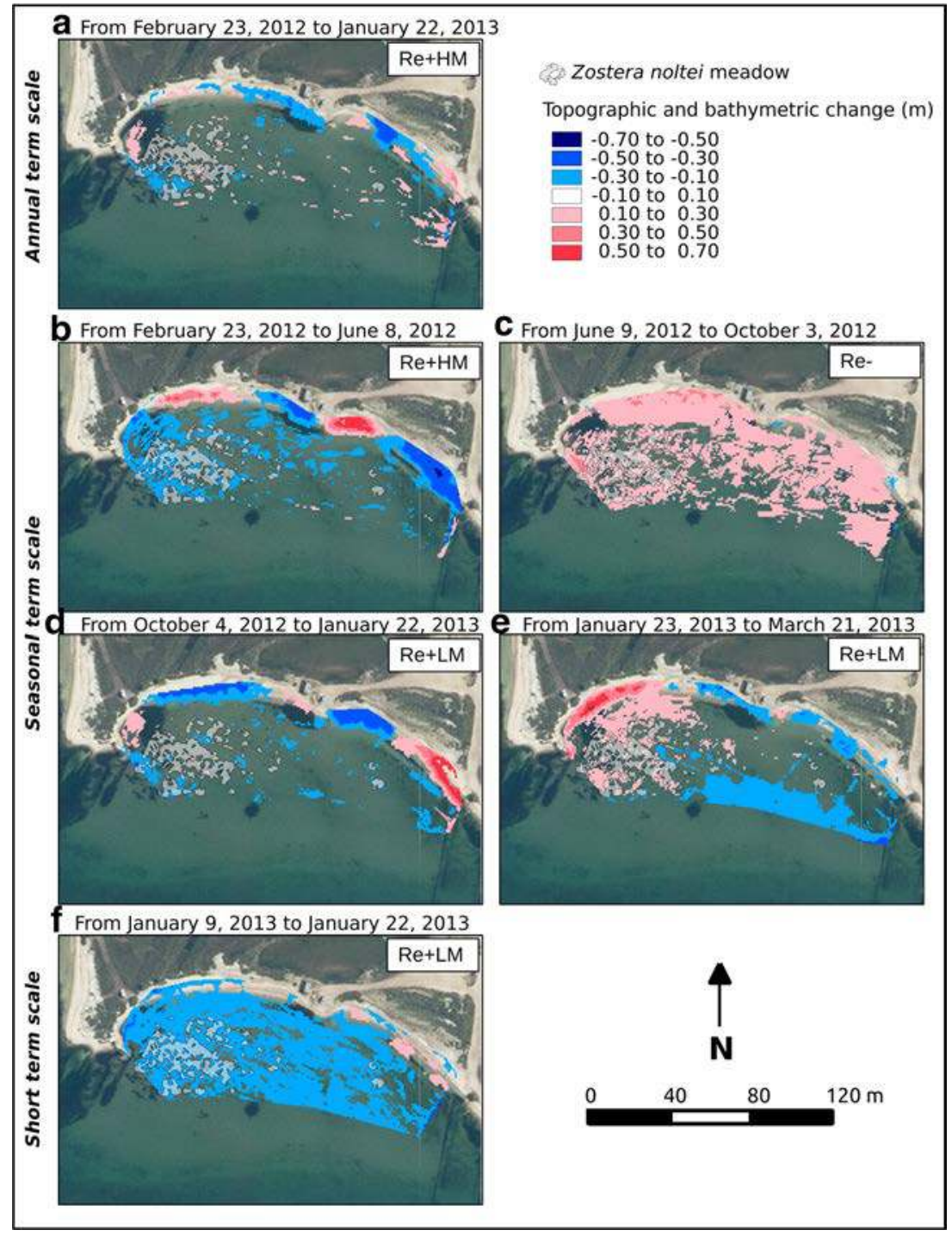

efficiency was monitored during this period. A particularly high recurrence of NNW winds (17.88\%) occurred.

At the shorter timescale (order of weeks), from January 9 , 2013 to January 22, 2013, the beach was characterized by an alternation of erosion and accretion, whereas erosion occurred in and outside the meadow (Fig. 10f). Winds of low morphogenic efficiency were highly recurrent, especially from WNW and NNW (respectively, 26.52 and 14.06\%).

\section{Discussion}

Notwithstanding the low shoot density and patchy nature of this meadow, the results from the various field experiments highlight clear interactions that bring out general patterns observed in similar ecosystems, but also more specific patterns that reflect not only the strongly wind-dominated character of the hydrodynamics and short wave fetches but also the influence of meadow patchiness. Overall, Berre Lagoon is exposed to wind waves much of the time that are expected to have a pronounced impact on meadows in shallow water. The field results and analyses orient our discussion towards the following points: (1) meadow-hydrodynamic interactions involving wave attenuation and current-wave patterns and (2) the influence of meadow patchiness on offshore and shoreline sedimentation and erosion.

\section{Meadow Hydrodynamics}

Comparing wave attenuation over a sandy transect and a transect in the meadow highlights the role of a low shoot-density $Z$. noltei meadow on wind-wave modifications based on field experiments. In the course of WExp1 in October 2012, wave heights and the wave attenuation rate decreased very close to the shore, over ST (over the section S4 s-S5 s) and above the meadow front edge over MT (over the section $\mathrm{S} 2 \mathrm{~m}-\mathrm{S} 3 \mathrm{~m}$ ) even though the section $\mathrm{S} 2 \mathrm{~m}-\mathrm{S} 3 \mathrm{~m}$ is deeper than the section $\mathrm{S} 4 \mathrm{~s}-$ 
S5 s $(-0.97$ to $-0.8 \mathrm{~m}$ against -0.81 to $-0.86 \mathrm{~m})$. The difference in water-level response above both transects (set-down over ST, set-up over MT) could reflect a difference in dissipation due to the presence of the meadow. The difference in wave attenuation patterns and water-level responses along both transects brings out the influence of this residual meadow on wave and water-level modifications. The study was carried out in a natural setting where all parameters are not under control, which was the case of the bathymetry. However, the differences in bathymetry between the two transects were not important enough to contribute to significant differences in wave attenuation comparable to those due to the effect of the meadow.

Wave attenuation has been seen to depend on offshore $H_{s}$, which depends in turn on wind intensity. These relationships are not linear because they are modulated by other factors, especially wind orientation relative to the bay, and wave periods. At equivalent wind speeds, and depending on $H_{s}$, wave period, and wind direction relative to bay orientation, wave attenuation differs. Between 8 and $11 \mathrm{~m} / \mathrm{s}$, NW and SE winds generate wind waves that are smaller and with shorter periods than those of $\mathrm{W}$ winds. Waves generated by NW wind (8$11 \mathrm{~m} / \mathrm{s})$ are small, despite having the longest fetch $(12 \mathrm{~km})$, and are refracted around the West Cape before entering the bay (Fig. 1b): they are not impacted by the meadow. Waves generated by SE wind $(8-11 \mathrm{~m} / \mathrm{s})$, which impinge directly on the bay but which develop over a short fetch $(4 \mathrm{~km})$, are small and are only impacted by the back part of the meadow. Waves generated by $\mathrm{W}$ wind $(8-11 \mathrm{~m} / \mathrm{s})$ also need to undergo some refraction around the West Cape to enter the bay but have a longer fetch $(8 \mathrm{~km})$. Since they have the highest $H_{s}$ at the entrance of the bay, they are impacted throughout the transect, and especially above the meadow front. All the attenuation patterns reported in the "Wave Attenuation Across the Meadow" section concern a relatively dense meadow considering the meadow biometric characteristics in the course of WExp2. For a less dense meadow with similar leaf length values, the response could be different. During WExp1, the 10-m/s SE winds generated waves that propagated above a less dense meadow. Waves were attenuated above the meadow front edge but not above the back edge. Wave attenuation rates for this wind direction and speed were slightly higher during WExp2 than WExp1. These results are confirmed by several other studies that have related wave attenuation to wave characteristics, meadow geometry, and meadow biometry (Méndez et al. 1999; Mendez and Losada 2004; Chen et al. 2007; Cavallaro et al. 2011; Paul and Amos 2011). Paul and Amos (2011) also showed a dependence of energy dissipation on Z. noltei shoot density in addition to hydrodynamics. Wind speed and, above all, wind direction control wave generation and propagation in fetch-limited areas, and are essential considerations in the interactions of hydrodynamics with seagrass meadows. Studies on hydrodynamic interactions with vegetation in fetch-limited settings should thus be conducted at a large enough scale that integrates wind characteristics, as has been done in our study, but also in those of Worcester (1995), and, more recently, Hansen and Reidenbach $(2012,2013,2017)$.

The wave attenuation rates calculated over the four sections in Berre Point are representative of what has been observed in the literature. Several studies have documented stronger wave attenuation in vegetated areas when wave heights were high and water levels low (water levels: Stratigaki et al. (2011), Koftis et al. (2013), and Manca et al. (2012), over mimics of P. oceanica in a flume study; John et al. (2016), in a flume study on mimics of Enhalus acoroides). In our dataset, the wave period seems less related to wave attenuation outside of the meadow than within. Over the offshore non-vegetated section, wave attenuation showed a slight tendency to decrease with wave height and period. In contrast, above the meadow front section (and to a lower extent, over other vegetated sections), wave attenuation tended to increase with wave height and period. Other authors (e.g., Lowe et al. (2007), on artificial canopies; Koftis et al. (2013) and Manca et al. (2012), on P. oceanica mimics; Paul and Amos (2011), on in situ Z. noltei; or Hansen and Reidenbach (2013), on in situ Z. marina) have observed a larger attenuation of longer waves due to the presence of vegetation. This evolution of wave attenuation along the transect highlights the importance of the meadow front edge in this process. A modeling approach, unfortunately out of the scope of this paper, could help to disentangle the role of the meadow itself, that of the bed, and even of bed forms linked to the presence of the meadow (e.g., mat-like forms).

Our dataset shows that only the offshore non-vegetated section always exhibited a positive exponential wave decay rate and, thus, wave attenuation, whereas vegetated sections showed wave attenuation for part of the measurements but also wave shoaling, especially for low waves with short periods combined with an increase in water depth (Figs. 6 and 7). This appears logical since wave period and water level are recognized as control factors on wave attenuation by vegetation, although most of the other authors that have used the exponential wave decay rate did not observe shoaling. This could be attributed to other local parameters such as the state of degradation of the meadow in Berre Lagoon.

Over this degraded $Z$. noltei meadow, we calculated positive wave decay rates reaching $0.018 \mathrm{~m}$ over the offshore nonvegetated section, $0.042 \mathrm{~m}$ over the meadow front section, $0.03 \mathrm{~m}$ over the in-meadow section, and $0.035 \mathrm{~m}$ over the meadow back edge. As stated earlier, the strongest wave attenuation was observed over the meadow front section. To our knowledge, this has rarely been described by other authors working on successive sections over vegetation, and who have generally observed an exponential decay of wave height along the vegetation transect (in salt marshes for Jadhav and Chen (2012); in mimics of seagrasses for John et al. (2012)). However, in a study of wave attenuation on successive sections along a salt-marsh transect, Paquier et al. (2016) observed a 
higher wave decay rate over the front of the marsh but only during rising tide; they attributed this to a lower water level at rising tide than during high tide (when the most significant wave attenuation occurred further inland in the marsh).

Several authors have evaluated wave attenuation using the exponential decay rate (e.g., Anderson and Smith 2014; Coulombier et al. 2012; Jadhav and Chen 2012; Manca et al. 2012; Paquier et al. 2016). Table 2 summarizes values of wave attenuation using the exponential decay rate calculated by various authors as well as the conditions in which they were observed. The values calculated over the offshore non-vegetated section in Berre Lagoon are similar to those reported by Coulombier et al. (2012) over a sand flat fronting a salt marsh. The positive wave attenuation rates observed in this study attained values similar to those obtained in $P$. oceanica mimics and salt marsh vegetation (mimics or real), with the exception of the salt marsh study of Jadhav and Chen (2012) during a hurricane $\left(K_{i}\right.$ reached $\left.0.055 \mathrm{~m}\right)$. A degraded meadow, such as that of Berre Lagoon, seems to have the same ability to attenuate waves as vegetation types presenting longer and larger leaves and showing a lower flexibility, especially when water levels are moderate and waves relatively high and long. This highlights the importance of preserving seagrass meadows, even degraded. However, the influence of such degraded meadows on higher and longer waves than those measured in Berre Lagoon will need to be evaluated.

Gambi et al. (1990) and Lefebvre et al. (2010) described the vertical profile in the presence of a subaquatic meadow and defined three layers: (1) an Above-Canopy Layer (ACaL), where current velocity is important and TKE low; (2) a Transition Zone Canopy Layer (TZCaL), at the canopy/water interface, where current velocity increases and TKE is high; and (3) a within Canopy Layer (CaL) with low and relatively constant current velocity and low TKE. To define the widths of the TZCaL and the CaL, we need to estimate the meadow canopy height. In our field study (movie available on http://www. gladys-littoral.org/en/resume/anne-eleonore-paquier), we observed that leaves moved under wave influence but were also deflected by currents. Leaf bending was observed by Boller and Carrington (2006), Paul et al. (2012), and Fonseca et al. (1982). An oscillatory movement of the canopy under unidirectional flow was described by Ackerman and Okubo (1993) as a "monami," a fluctuation caused by the hydroelasticity of plants. Lefebvre et al. (2010) observed large-scale flow oscillations at the canopy surface that can be related to the canopy monami. Even though the canopy movement in the field (Movie 1) could have been influenced by the monami, we consider that the bending of the leaves was modulated by passing waves. This modulation was weak when the current was strong because the mean bending angle increased with current speed (Fonseca et al. 1982). Therefore, during a weak WNW wind event such as that of WCExp2 - phase 1, the canopy height should be approximated as the mean value of leaf length of $Z$. noltei, whereas during a strong NW event (WCExp1), we can estimate the instantaneous meadow canopy height as the half leaf length, i.e., $0.1 \mathrm{~m}$.

The ACaL identified by Gambi et al. (1990) and Lefebvre et al. (2010), wherein current velocity is important and TKE low incorporates both the WiDCL and the WiDWICL, is described in the "Results" section. The definition of sub-layers of the ACaL as we have done here enables a better understanding of the interactions of wind and waves in the upper part of the water column. The TZCaL was clearly identified as a shear layer with a significant increase in current velocity and TKE above the meadow canopy during WCExp 1 and WCExp3, thus highlighting the meadow impact (Figs. 8 $\mathrm{a}^{\prime}$, $a^{\prime \prime \prime}, c^{\prime}, c^{\prime \prime \prime}$ and $\left.9 a, b\right)$. A possible explanation could be that meadow leaves move under the effect of a stronger contribution of wind waves which can create a change in current direction that could be associated with a skimming flow

Table 2 Exponential wave decay rates in Berre Lagoon meadow and cited in other studies, and respective environmental settings

\begin{tabular}{|c|c|c|c|c|}
\hline Authors & Data & Vegetation type & Main varying parameters & Wave decay rate $K_{i}$ (in m) \\
\hline Present study & Field study & Seagrass: Zostera noltei & $\begin{array}{l}\text { Wave parameters, water level, at successive } \\
\text { sections (4) along a vegetated transect } \\
\text { that includes a non-vegetated section }\end{array}$ & $\begin{array}{l}-0.03 \text { to } 0.04 \text { ( } 0.004 \text { to } 0.018 \\
\quad \text { along the non-vegetated section) }\end{array}$ \\
\hline $\begin{array}{l}\text { Manca } \\
\text { et al. (2012) }\end{array}$ & Flume study & $\begin{array}{l}\text { Seagrass: Posidonia } \\
\text { oceanica mimics }\end{array}$ & Shoot density, wave period, submersion ratio & 0.003 to 0.035 \\
\hline $\begin{array}{l}\text { Jadhav and } \\
\text { Chen (2012) }\end{array}$ & Field study & $\begin{array}{l}\text { Salt marsh vegetation: } \\
\text { Spartina alterniflora }\end{array}$ & $\begin{array}{l}\text { Successive sections ( } 3 \text { ) in the marsh, wave } \\
\text { parameters, water level }\end{array}$ & 0.02 to 0.055 \\
\hline $\begin{array}{l}\text { Anderson and } \\
\text { Smith (2014) }\end{array}$ & Flume study & $\begin{array}{l}\text { Salt marsh vegetation: } \\
\quad \text { Spartina alterniflora mimics }\end{array}$ & Wave parameters, submersion ration & 0.006 to 0.019 \\
\hline $\begin{array}{l}\text { Coulombier } \\
\text { et al. (2012) }\end{array}$ & Field study & $\begin{array}{l}\text { Salt marsh vegetation: } \\
\text { Spartina alterniflora }\end{array}$ & $\begin{array}{l}\text { Wave parameters, water level, vegetation } \\
\text { biometry, successive sections (2) along } \\
\text { a vegetated transect including a } \\
\text { non-vegetated section }\end{array}$ & $\begin{array}{l}0.0025 \text { to } 0.021 \text { ( } 0.0005 \text { to } 0.018 \\
\quad \text { along the non-vegetated section) }\end{array}$ \\
\hline $\begin{array}{l}\text { Paquier } \\
\quad \text { et al. (2016) }\end{array}$ & Field study & $\begin{array}{l}\text { Salt marsh vegetation: Spartina } \\
\quad \text { alterniflora and Spartina patens }\end{array}$ & $\begin{array}{l}\text { Wave parameters, water level, successive } \\
\text { sections in the marsh (combined with a } \\
\text { change in vegetation type) }\end{array}$ & 0.01 to 0.047 \\
\hline
\end{tabular}


(concentration of energy deflected by the meadow), as observed by Gambi et al. (1990) or Peralta et al. (2008). This skimming flow could also be linked to wave attenuation and not only to redirection of the deflected current.

In the course of WCExp1, the CaL was characterized by unstable flow direction, low current velocity, and low TKE above the layer potentially impacted by side-lobe interference (Figs. 8 and 9). During WCExp2 and WCExp3, the few millimeters characterized by a low current velocity and TKE can hardly be interpreted as indicating the presence of the CaL even though it shows that processes of current modification are certainly ongoing. WCExp1 highlights the strong attenuation effect of the meadow on water flow. Notwithstanding the prevalence at depth of a strong current during WCExp1, the CaL attained a width of $0.1 \mathrm{~m}$. But for WCExp2 and WCExp3, it is difficult to conclude on the existence of this layer due to the possible side-lobe interference in the depth bin $(0.065 \mathrm{~m})$ closest to the bed. However, during these experiments, wave periods were lower than during WCExp1. As short waves are expected to be less attenuated than long waves, we expect the thickness of the $\mathrm{CaL}$ to be lower than during WCExp1: the motion of leaves at high frequency could decrease the resistance of the meadow to the flow, and hence, the CaL thickness.

Hansen and Reidenbach (2013) compared current velocity within a $Z$. marina canopy ( $0.1 \mathrm{~m}$ above the bed) and above the canopy $(0.5 \mathrm{~m})$ in South Bay, a shallow coastal bay in Virginia, USA. This meadow exhibited, depending on the season, a canopy height of 15 to $25 \mathrm{~cm}$ and a density of 310 to 560 shoots per $\mathrm{m}^{2}$. Even though Z. marina is different from $Z$. noltei in terms of leaf biometry ( $Z$. marina leaves are two to three times larger and $Z$. marina also has a larger canopy height), we consider that a comparison between both species is possible. The results reported by Hansen and Reidenbach (2013) showed a current velocity reduction in the canopy of 65 to $80 \%$, with a maximum in June, when canopy was fully developed. In the $Z$. noltei meadow studied here, we evaluate this reduction as varying between 32 and $72 \%$ depending on the hydrodynamic conditions. The lower values observed in Berre Lagoon could be linked to the meadow species, the measurement season (spring in Berre Lagoon and summer in South Bay), and the state of degradation of the Berre Lagoon meadow. Currents in the lagoon could also be attenuated by the movement of leaves under the effect of passing waves.

\section{Meadow Patchiness and Erosion and Sedimentation}

Luhar and Nepf (2013) have shown that a high number of patches affect wave and current attenuation by increasing the interfacial area (increase in meadow edges). At Berre Point, however, the meadow is probably not extensive enough for such patchiness to be effective in significantly contributing to the attenuation of waves and currents. In such circumstances, patchiness is more susceptible to encourage erosion (around patches), as reported by Bouma et al. (2007) and Bos et al. (2007). This aspect has not been investigated in Berre Lagoon. When moderate hydrodynamic conditions prevail, the high shoot density in summer favors, however, accretion within the meadow and on the beach, as currents are nevertheless slowed down and waves attenuated, leading to the trapping of sediment (Fig. 10c), as observed also by Bos et al. (2007), Van Katwijk et al. (2010), and Ganthy et al. (2011b). The longer leaf lengths in summer reflecting the low productivity of the Berre meadow can, paradoxically, be a factor favorable to meadow sediment trapping. Under particularly strong hydrodynamic conditions, high shoot density and long leaf lengths can also favor accretion on the beach and in the back of the meadow concomitantly with erosion in front of it (Fig. 10e). This shelter effect in the back of the meadow is highlighted by the grain-size distribution: we observed that grain sizes were always finest in the back of the meadow. Bouma et al. (2007) and Bos et al. (2007) observed accretion within a high shoot-density meadow and erosion in front of the meadow and between patches. We observed the same pattern even though the Berre Point meadow is residual and has a patchy distribution.

It has been shown that the beach behind the Berre Lagoon meadow exhibits a process of "rotation" generated by waves from opposite directions (Paquier et al. 2014). On some beaches, especially bay beaches, it is not uncommon for seasonal or longer-term changes in the predominant direction of wave approach to induce changes in longshore drift. Such reversals in longshore drift commonly result in "beach rotation" (Short and Masselink 1999), which is the periodic lateral movement of sand towards alternating ends of the embayed beach. The process results in erosion at one end of the beach, while the other accretes. In Berre Lagoon, the meadow is expected to play a role in beach dynamics since erosion was observed when shoot density and leaf lengths were lowest (Fig. 10b, f), and sedimentation was observed on the beach but also in the back of the meadow when shoot density and leaf lengths increased despite particularly strong hydrodynamic conditions (Fig. 10e).

Regarding the sustainability of the meadow in the particular hydrodynamic context of Berre Lagoon, our results showed a rapid response of waves to strong wind influence in this semi-enclosed and highly fetch-limited setting. Only wind waves higher than $0.4 \mathrm{~m}$ offshore are attenuated over this residual meadow. We expect that wind waves damage the meadow before and in the wave attenuation area, whereas currents erode the edges of the meadow and enhance the area of impact of wind waves by reducing wave attenuation (Paul et al. 2012). Winds are active throughout the year as mentioned above, and especially during winter and spring. But spring is the growing period of $Z$. noltei. The meadow is thus impacted all year long but particularly during its growing period. The combination of recurrent wind waves and currents could therefore be the factor constraining extension of the Berre Lagoon meadow. 
An aspect not investigated in our study but observed in the field was significant turbidity that generally occurred half an hour after the first wind gusts. This important resuspension is linked to the generation of wind waves at Berre Point. Cabaço and Santos (2007) reported, for instance, important shoot mortality following burial of a meadow under $4 \mathrm{~cm}$ of settled sediments. Our study showed that sediments resuspended during the strong wind events in Berre Point are stored within and at the back of the meadow.

\section{Conclusion}

The seagrass meadow studied here is a residual meadow as shown by its biometric evolution in the course of the year. In our measurements, the interactions between this residual meadow and hydrodynamics are characterized by a reduction of current velocity in the meadow canopy, the generation of a skimming flow above the canopy, and the attenuation of waves in the meadow, especially over the meadow front. Seabed evolution was also observed at a longer timescale and related to the intensity and frequency of wind and wave agitation. This meadow, although residual, has the ability to reduce current velocities, attenuate waves, limit erosion of its seabed, and, thus, to contribute to protection against erosion of the shore and favor deposition of sediments onshore.

The role of the residual meadow on wave attenuation has been demonstrated by the comparison of two transects: a meadow transect (MT) and a sandy transect (ST). This comparison showed that the meadow front edge had a predominant role on wave attenuation since waves were attenuated preferentially over the meadow front over MT and more shoreward over ST, despite the more important depth of the meadow front compared to the area of attenuation over ST. This comparison also brought out a difference in the response of water level over both transects (set-down over ST, set-up over MT), certainly linked to the presence of the meadow.

The analysis of several storm events propagating over a transect across the meadow has also enabled a better understanding of wave attenuation over such a residual meadow. Winds control the hydrodynamics in the lagoon context of the meadow, and, thus, hydrodynamic interactions with the latter. At the timescale of a wind event, the interactions of hydrodynamics with the residual meadow depend on wind speed and wind direction:

- Without wind, agitation is weak in the study area and there are no interactions between the meadow and hydrodynamics. When wind blows over the lagoon, wind waves are formed, propagate into the lagoon, and start to interact with the meadow. With increase in wind speed, wave height increases as does current velocity.

- Even though wave height varies offshore as a function of wind speed and fetch length, wind direction relative to bay orientation is also an important factor. The interactions between the meadow and hydrodynamics (waves and currents) are initiated by wind and vary as a function of wind direction outside of the bay. For a similar wind speed, a wind generating waves propagating with a low refraction into the bay (the case of a W wind) will generate the strongest interactions with the meadow than a wind with a longer fetch but generating waves that are strongly refracted by the bay morphology (NW wind).

Wave height and period and water depth are also factors controlling wave attenuation in this degraded meadow since wave attenuation increases with wave height and period. Wave attenuation is most important above the meadow front edge. This role of the meadow front seems to be more important than in other vegetated settings for short waves, as has been shown in a comparison with other studies. However, for longer waves, particularly when combined with a reduced water column, the degraded meadow allows a similar wave attenuation to that observed in other studies on mimics of seagrass or in salt-marsh vegetation.

The dataset presented here seems to show that currentmeadow interactions are less controlled by wind direction since the wind influence is mostly limited to the upper part of the water column.

Finally, our results have shown that a degraded meadow can participate in coastal protection against erosion, although this relationship is seasonal. Erosion was observed when shoot density and leaf lengths were lowest, and sedimentation on the beach but also in the back of the meadow when shoot density and leaf lengths increased, even when particularly energetic hydrodynamic conditions prevailed. Notwithstanding low shoot density and patchiness, a residual meadow can, thus, play a role in beach dynamics and sedimentation.

Acknowledgements We thank the reviewers and the Associate Editor for their constructive comments and suggestions which have been helpful in improving the manuscript. GIPREB staff (Guillaume Bernard, Nicolas Mayot, Florian Dandine, Vincent Faure) are thanked for the meadow mapping, field assistance, and tide data. Météo France provided the wind data. GLADYS, the French coastal research group, provided some of the instruments deployed in the course of the study. Members of GLADYS (especially Damien Sous), Doriane Delanghe and Thomas Stieglitz, are thanked for the useful discussions.

Funding A.E. Paquier was provided $\mathrm{PhD}$ funding by the "Provence Alpes Côte d'Azur" Region, the European Union, GIPREB (Gestion intégrée, prospective, restauration Etang de Berre), and support from OSU-Institut Pythéas.

\section{References}

Ackerman, J.D., and A. Okubo. 1993. Reduced mixing in a marine macrophyte canopy. Functional Ecology 7 (3): 305-309.

Anderson, M.E., and J.M. Smith. 2014. Wave attenuation by flexible idealized salt marsh vegetation. Coastal Engineering 83: 82-92. https://doi.org/10.1016/j.coastaleng.2013.10.004. 
Asano, T., S. Tsutsui, and T. Sakai. 1988. Wave damping characteristics due to seaweed. Proceedings of the 35 th coastal engineering conference in Japan. JSCE 138-142. (in Japanese).

Asano, T., H. Deguchi, and N. Kobayashi. 1992. Interactions between water waves and vegetation. Proceedings of the 23 rd International Conference on Coastal Engineering. ASCE. 2710-2723.

Auby, I., and P.-J. Labourg. 1996. Seasonal dynamics of Zostera noltii hornem. In the bay of arcachon (France). Journal of Sea Research 35 (4): 269-277. https://doi.org/10.1016/S1385-1101(96)90754-6.

Barbier, E.B., E.W. Koch, B.R. Silliman, et al. 2008. Coastal ecosystem-based management with nonlinear ecological functions and values. Science 319 (5861): 321-323. https://doi.org/ 10.1126/science. 1150349 .

Bernard, G., C.F. Boudouresque, and P. Picon. 2007. Long term changes in Zostera meadows in the Berre lagoon (Provence, Mediterranean Sea). Estuarine, Coastal and Shelf Science 73 (3-4): 617-629. https://doi.org/10.1016/j.ecss.2007.03.003.

Boller, M.L., and E. Carrington. 2006. In situ measurements of hydrodynamic forces imposed on Chondrus crispus Stackhouse. Journal of Experimental Marine Biology and Ecology 337 (2): 159-170. https://doi.org/10.1016/j.jembe.2006.06.011.

Borsje, B.W., B.K. van Wesenbeeck, F. Dekker, P. Paalvast, T.J. Bouma, M.M. van Katwijk, and M.B. de Vries. 2011. How ecological engineering can serve in coastal protection. Ecological Engineering 37 (2): 113-122. https://doi.org/10.1016/j.ecoleng.2010.11.027.

Bos, A.R., T.J. Bouma, G.L.J. de Kort, and M.M. van Katwijk. 2007. Ecosystem engineering by annual intertidal seagrass beds: Sediment accretion and modification. Estuarine, Coastal and Shelf Science 74 (1-2): 344-348. https://doi.org/10.1016/j.ecss.2007.04.006.

Boscutti, F., I. Marcorin, M. Sigura, E. Bressan, F. Tamberlich, A. Vianello, and V. Casolo. 2015. Distribution modeling of seagrasses in brackish waters of Grado-Marano lagoon (northern Adriatic Sea). Estuarine, Coastal and Shelf Science 164: 183-193. https://doi.org/ 10.1016/j.ecss.2015.07.035.

Boudouresque, C.F., G. Pergent, C. Pergent-Martini, S. Ruitton, T. Thibaut, and M. Verlaque. 2016. The necromass of the Posidonia oceanica seagrass meadow: Fate, role, ecosystem services and vulnerability. Hydrobiologia 781 (1): 25-42. https://doi.org/10.1007/ s10750-015-2333-y.

Bouma, T.J., M.B. De Vries, E. Low, G. Peralta, I.C. Tanczos, J. Van de Koppel, and P.M.J. Herman. 2005. Trade-offs related to ecosystem engineering : A case study on stiffness of emerging macrophytes. Ecology 86 (8): 2187-2199. https://doi.org/10.1890/04-1588.

Bouma, T.J., L.A. van Duren, S. Temmerman, T. Claverie, A. Blanco-Garcia, T. Ysebaert, and P.M.J. Herman. 2007. Spatial flow and sedimentation patterns within patches of epibenthic structures: Combining field, flume and modelling experiments. Continental Shelf Research 27 (8): 1020-1045. https://doi.org/ 10.1016/j.csr.2005.12.019.

Bradley, K., and C. Houser. 2009. Relative velocity of seagrass blades: Implications for wave attenuation in low-energy environments. Journal of Geophysical Research - Earth Surface 114. https://doi. org/10.1029/2007JF000951

Cabaço, S., and R. Santos. 2007. Effects of burial and erosion on the seagrass Zostera noltii. Journal of Experimental Marine Biology and Ecology 340 (2): 204-212. https://doi.org/10. 1016/j.jembe.2006.09.003.

Cavallaro, L., C.L. Re, G. Paratore, A. Viviano, and E. Foti. 2011. Response of Posidonia oceanica to wave motion in shallow-waters. Preliminary experimental results. Coastal Engineering Proceedings 1 (32): 49. https://doi.org/10.9753/icce.v32.waves.49.

Chen, S.-N., L. Sanford, E. Koch, F. Shi, and E. North. 2007. A nearshore model to investigate the effects of seagrass bed geometry on wave attenuation and suspended sediment transport. Estuaries and Coasts 30 (2): 296-310. https://doi.org/10.1007/BF02700172.
Chevallier, A. 1916. L'étang de Berre. Annales de l'Institut Océanographique VII: 90.

Christianen, M. J. A., J. van Belzen, P. M. J. Herman, M. M. van Katwijk, L. P. M. Lamers, P. J. M. van Leent, and T. J. Bouma. 2013. Lowcanopy seagrass beds still provide important coastal protection services. PLoS One 8. https://doi.org/10.1371/journal.pone.0062413.

Coulombier, T., U. Neumeier, and P. Bernatchez. 2012. Sediment transport in a cold climate salt marsh (St. Lawrence estuary, Canada), the importance of vegetation and waves. Estuarine, Coastal and Shelf Science 101: 64-75. https://doi.org/10.1016/j.ecss.2012.02.014.

De Boer, W.F. 2007. Seagrass-sediment interactions, positive feedbacks and critical thresholds for occurrence: A review. Hydrobiologia 591 (1): 5-24. https://doi.org/10.1007/s10750-007-0780-9.

Elginoz, E., M.S. Kabdasli, and A. Tanik. 2011. Effects of Posidonia oceanica seagrass meadows on storm waves. Journal of Coastal Research, SI 64: 373-377.

Fonseca, M.S., and J.A. Cahalan. 1992. A preliminary evaluation of wave attenuation by four species of seagrass. Estuarine, Coastal and Shelf Science 35 (6): 565-576. https://doi.org/10. 1016/S0272-7714(05)80039-3.

Fonseca, M.S., and J.S. Fisher. 1986. A comparison of canopy friction and sediment movement between four species of seagrass with reference to their ecology and restoration. Marine Ecology Progress Series 29: 15-22. https://doi.org/10.3354/meps029015.

Fonseca, M.S., and M.A.R. Koehl. 2006. Flow in seagrass canopies: The influence of patch width. Estuarine, Coastal and Shelf Science 67 (1-2): 1-9. https://doi.org/10.1016/j.ecss.2005.09.018.

Fonseca, M.S., J.S. Fisher, J.C. Zieman, and G.W. Thayer. 1982. Influence of the seagrass, Zostera marina L., on current flow. Estuarine, Coastal and Shelf Science 15 (4): 351-364. https://doi. org/10.1016/0272-7714(82)90046-4.

Gambi, M.C., A.R.M. Nowell, and P.A. Jumars. 1990. Flume observations on flow dynamics in Zostera marina (eelgrass) beds. Marine Ecology Progress Series 61: 159-169. https://doi.org/10.3354/meps061159.

Ganthy, F., A. Sottolichio, and R. Verney. 2011a. The stability of vegetated tidal flats in a coastal lagoon through quasi in-situ measurements of sediment erodibility. Journal of Coastal Research, SI 64: 1500-1504.

Ganthy, F., A. Sottolichio, and R. Verney. 2011b. Seasonal modification of tidal flat sediment dynamics by seagrass meadows of Zostera noltii (Bassin d'Arcachon, France). Journal of Marine Systems. https://doi.org/10.1016/j.jmarsys.2011.11.027.

Gillanders, B. 2006. Seagrasses, Fish, and Fisheries. In Seagrasses: Biology, Ecology and Conservation, 503-536. Netherlands: Springer.

Gratiot, N., A. Gardel, and E.J. Anthony. 2007. Trade-wind waves and mud dynamics on the French Guiana coast, South America: Input from ERA-40 wave data and field investigations. Marine Geology 236 (1-2): 15-26. https://doi.org/10.1016/j.margeo.2006.09.013.

Hansen, J.C.R., and M. Reidenbach. 2012. Wave and tidally driven flows in eelgrass beds and their effect on sediment suspension. Marine Ecology Progress Series 448: 271-287. https://doi.org/ 10.3354/meps09225.

Hansen, J.C.R., and M. Reidenbach. 2013. Seasonal growth and senescence of a Zostera marina seagrass meadow alters wave-dominated flow and sediment suspension within a Coastal Bay. Estuaries and Coasts 36 (6): 1099-1114. https://doi.org/10.1007/s12237-013-9620-5.

Hansen, J.C.R., and M. Reidenbach. 2017. Turbulent mixing and fluid transport within Florida bay seagrass meadows. Advances in Water Resources 108 : 205-215. https://doi.org/10.1016/j.advwatres.2017.08.001.

Horikawa, K. 1988. Nearshore Dynamics and Coastal Processes: Theory, Measurement and Predictive Models, Tokyo. University of Tokyo Press.

Jadhav, R.S. and Q. Chen, 2012. Field investigation of wave dissipation over salt marsh vegetation during tropical cyclone. Coastal Engineering Proceedings, [S.1.], n. 33, p. waves. 41, Oct. 2012. ISSN 2156-1028. 
John, B.M., K.G. Shirlal, S. Rao, and C. Rajasekaran. 2016. Effect of artificial seagrass on wave attenuation and wave run-up. International Journal of Ocean and Climate Systems 7 (1): 14-19. https://doi.org/10.1177/1759313115623163.

Kobayashi, N., A.W. Raichle, and T. Asano. 1993. Wave attenuation by vegetation. Journal of Waterway, Port, Coastal, and Ocean Engineering. 119 (1): 30-48. https://doi.org/10.1061/(ASCE)0733950X(1993)119:1(30).

Koftis, T., P. Prinos, and V. Stratigaki. 2013. Wave damping over artificial Posidonia oceanica meadow: A large-scale experimental study. Coastal Engineering 73: 71-83. https://doi.org/10.1016/j. coastaleng.2012.10.007.

Lefebvre, A., C.E.L. Thompson, and C.L. Amos. 2010. Influence of Zostera marina canopies on unidirectional flow, hydraulic roughness and sediment movement. Continental Shelf Research 30 (16): 1783-1794. https://doi.org/10.1016/j.csr.2010.08.006.

Lowe, R. J., J. L. Falter, J. R. Koseff, S. G. Monismith, and M. J. Atkinson. 2007. Spectral wave flow attenuation within submerged canopies: Implications for wave energy dissipation. Journal of Geophysical Research, Oceans 112. https://doi.org/10.1029/ 2006JC003605

Luhar, M., and H. Nepf. 2013. From the blade scale to the reach scale: A characterization of aquatic vegetative drag. Advances in Water Resources 51: 305-316. https://doi.org/10.1016/j. advwatres.2012.02.002.

Madsen, J.D., P.A. Chambers, W.F. James, E.W. Koch, and D.F. Westlake. 2001. The interaction between water movement, sediment dynamics and submersed macrophytes. Hydrobiologia 444 (1/3): 71-84. https://doi.org/10.1023/A:1017520800568.

Manca, E., I. Cáceres, J.M. Alsina, V. Stratigaki, I. Townend, and C.L. Amos. 2012. Wave energy and wave-induced flow reduction by full-scale model Posidonia oceanica seagrass. Continental Shelf Research 50-51: 100-116. https://doi.org/ 10.1016/j.csr.2012.10.008.

Mendez, F.J., and I.J. Losada. 2004. An empirical model to estimate the propagation of random breaking and nonbreaking waves over vegetation fields. Coastal Engineering 51 (2): 103-118. https://doi.org/ 10.1016/j.coastaleng.2003.11.003.

Méndez, F.J., I.J. Losada, and M.A. Losada. 1999. Hydrodynamics induced by wind waves in a vegetation field. Journal of Geophysical Research 104 (C8): 18383-18396. https://doi.org/10.1029/ 1999JC900119.

Möller, I., T. Spencer, J.R. French, D.J. Leggett, and M. Dixon. 1999. Wave transformation over salt marshes: A field and numerical modelling study from North Norfolk, England. Estuarine, Coastal and Shelf Science 49 (3): 411-426. https:// doi.org/10.1006/ecss.1999.0509.

Neumeier, U. 2007. Velocity and turbulence variations at the edge of saltmarshes. Continental Shelf Research 27 (8): 1046-1059. https://doi.org/10.1016/j.csr.2005.07.009.

Ondiviela, B., I.J. Losada, J.L. Lara, M. Maza, C. Galván, T.J. Bouma, and J. van Belzen. 2014. The role of seagrasses in coastal protection in a changing climate. Coastal Engineering 87: 158-168. https://doi. org/10.1016/j.coastaleng.2013.11.005.

Paquier, A.E., S. Meulé, E.J. Anthony, and G. Bernard. 2014. Sedimentation and erosion patterns in a low shoot-density Zostera noltii meadow in the fetch-limited Berre lagoon, Mediterranean France. Journal of Coastal Research, SI 70: 563-567. https://doi. org/10.2112/SI70-095.1.

Paquier, A.E., J. Haddad, S. Lawler, and C.M. Ferreira. 2016. Quantification of the attenuation of storm surge components by a coastal wetland of the US mid Atlantic. Estuaries and Coasts 40 (4): 930-946. https://doi.org/10.1007/s12237-016-0190-1.

Paul, M., and C. L. Amos. 2011. Spatial and seasonal variation in wave attenuation over Zostera noltii. Journal of Geophysical Research, Oceans 116. https://doi.org/10.1029/2010JC006797.
Paul, M., T.J. Bouma, and C.L. Amos. 2012. Wave attenuation by submerged vegetation: Combining the effect of organism traits and tidal current. Marine Ecology Progress Series 444: 31-41. https://doi. org/10.3354/meps09489.

Peralta, G., L.A. van Duren, E.P. Morris, and T.J. Bouma. 2008. Consequences of shoot-density and stiffness for ecosystem engineering by benthic macrophytes in flow dominated areas : A hydrodynamic flume study. Marine Ecology Progress Series 368: 103115. https://doi.org/10.3354/meps07574.

Peterson, C.H., R.A. Luettich, F. Micheli, and G.A. Skilleter. 2004. Attenuation of water flow inside seagrass canopies of differing structure. Marine Ecology Progress Series 268: 81-92. https://doi. org/10.3354/meps268081.

Pujol, D., and H. Nepf. 2012. Breaker-generated turbulence in and above a seagrass meadow. Continental Shelf Research 49: 1-9. https://doi. org/10.1016/j.csr.2012.09.004.

Rigaud, S. 2011. Dynamique et Biodisponibilité des éléments traces métalliques dans les sédiments de l'étang de Berre. Ph.D. thesis. Université Paul Cézanne.

Sénéchal, N., H. Dupuis, P. Bonneton, H. Howa, and R. Pedreros. 2001. Observation of irregular wave transformation in the surf zone over a gently sloping sandy beach on the French Atlantic coastline. Oceanologica Acta 24 (6): 545-556. https://doi.org/10.1016/ S0399-1784(01)01171-9.

Seymour, R., M. Tegner, P. Dayton, and P. Parnell. 1989. Storm wave induced mortality of giant kelp, Macrocystis pyrifera, in southern California. Estuarine, Coastal and Shelf Science 28 (3): 277-292. https://doi.org/10.1016/0272-7714(89)90018-8.

Short, A.D., and G. Masselink. 1999. Embayed and structurally controlled beaches. In Handbook of beach and Shoreface Morphodynamics, ed. A.D. Short, 230-250. Chichester: John Wiley \& Sons Ltd.

Short, F., T. Carruthers, W. Dennison, and M. Waycott. 2007. Global seagrass distribution and diversity: A bioregional model. Journal of Experimental Marine Biology and Ecology 350 (1-2): 3-20. https://doi.org/10.1016/j.jembe.2007.06.012.

Soulsby, R. L., and J. D. Humphery. 1990. Field observations of wavecurrent interaction at the sea bed. In ed. O. T. Torum, A. Gudmestad, 413-428. Water Wave Kinematics.

Stapelton, D., and L. Huntley. 1995. Seabed stress Determainations using the inertial dissipation Dethord and the turbulent Kenetic energy method. Earth Surface Processes and Landforms 20 (9): 807-815. https://doi.org/10.1002/esp.3290200906.

Stora, G., and A. Arnoux. 1988. Effects on Mediterranean lagoon macrobenthos of a river diversion: Assessment and analytical review. In Natural and man-made hazards, ed. M.I. El-Sabh and T.S. Murty, 525-546. Netherlands: Springer.

Stratigaki, V., E. Manca, P. Prinos, I.J. Losada, J.L. Lara, M. Sclavo, C.L. Amos, I. Cáceres, and A. Sánchez-Arcilla. 2011. Large-scale experiments on wave propagation over Posidonia oceanica. Journal of Hydraulic Research 49 (sup1): 31-43. https://doi.org/10.1080/ 00221686.2011 .583388 .

Umgiesser, G., M. Sclavo, S. Carniel, and A. Bergamasco. 2004. Exploring the bottom stress variability in the Venice lagoon. Journal of Marine Systems 5 (1-4): 161-178. https://doi.org/10. 1016/j.jmarsys.2004.05.023.

Van Katwijk, M.M., A.R. Bos, D.C.R. Hermus, and W. Suykerbuyk. 2010. Sediment modification by seagrass beds: Muddification and sandification induced by plant cover and environmental conditions. Estuarine, Coastal and Shelf Science 89 (2): 175-181. https://doi. org/10.1016/j.ecss.2010.06.008.

Wanless, H.R. 1981. Fining-upwards sedimentary sequences generated in seagrass beds. Journal of Sedimentary Research 51: 445-454. https://doi.org/10.1306/212F 7 CA2-2B24-11 D 7 $8648000102 \mathrm{C} 1865 \mathrm{D}$. 
Waycott, M., C.M. Duarte, T.J.B. Carruthers, et al. 2009. Accelerating loss of seagrasses across the globe threatens coastal ecosystems. Proceedings of the National Academy of Sciences 106 (30): 12377-12381. https://doi.org/10.1073/pnas.0905620106.

Widdows, J., N.D. Pope, M.D. Brinsley, H. Asmus, and R.M. Asmus. 2008. Effects of seagrass beds (Zostera noltii and Z. marina) on nearbed hydrodynamics and sediment resuspension. Marine Ecology Progress Series 358: 125-126. https://doi.org/10.3354/meps07338.
Winterwerp, J.C., R.F. de Graaff, J. Groeneweg, and A.P. Luijendijk. 2007. Modelling of wave damping at Guyana mud coast. Coastal Engineering 54 (3): 249-261. https://doi.org/10.1016/j.coastaleng. 2006.08.012.

Worcester, S.E. 1995. Effects of eelgrass beds on advection and turbulent mixing in low current and low shoot-density environments. Marine Ecology Progress Series 126: 223-232. https://doi.org/10.3354/ meps 126223. 